\title{
Behaviors and Overlying Strata Failure Law for Underground Filling of a Gently Inclined Medium-Thick Phosphate Deposit
}

\author{
Xiaoshuang Li, ${ }^{1,2,3,4}$ Jiabo Geng, ${ }^{1}$ Qihang Li $\mathbb{D}^{1},{ }^{1}$ Weijun Tian, ${ }^{5}$ and Tao Zhou ${ }^{1}$ \\ ${ }^{1}$ School of Resources and Environmental Engineering, Jiangxi University of Science and Technology, Ganzhou, \\ Jiangxi 341000, China \\ ${ }^{2}$ School of Civil Engineering, Shaoxing University, Shaoxing, Zhejiang 312000, China \\ ${ }^{3}$ College of Civil Engineering, Qilu Institute of Technology, Jinan, Shandong 250200, China \\ ${ }^{4}$ Sinosteel Maanshan General Institute of Mining Research Co. Ltd., Maanshan, Anhui 243000, China \\ ${ }^{5}$ State Key Laboratory of Coal Mine Disaster Dynamics and Control, Chongqing University, Chongqing 400030, China
}

Correspondence should be addressed to Qihang Li; 6720190072@mail.jxust.edu.cn

Received 6 May 2021; Accepted 5 July 2021; Published 17 July 2021

Academic Editor: Qianqian Wang

Copyright ( $\odot 2021$ Xiaoshuang Li et al. This is an open access article distributed under the Creative Commons Attribution License, which permits unrestricted use, distribution, and reproduction in any medium, provided the original work is properly cited.

In this study, the No. 6 pit in the eastern mining area of the Jinning phosphate mine in China was taken as the research background. In order to reduce the cost of filling, an improved pillarless sublevel caving method is proposed. This method greatly improves the ore recovery rate by adding a recovery route. In addition, the combination of similar material simulation experiments and numerical simulations (discrete element and universal distinct element code) revealed the deformation and failure laws of the surrounding roof rock and the characteristics of the surface subsidence. The results indicate the following. (1) The similar simulation experimental results indicate that the deformation of the overlying rock layer originated from the direct roof of the goaf and gradually developed into the deep part of the rock layer. An irregular stepped caving zone formed in the goaf. The maximum surface subsidence was located above the phosphorus orebody, and it gradually decreased toward both sides. As the stope approached propulsion, the location of the maximum subsidence gradually moved toward the propulsion direction. (2) The numerical results revealed that the displacement of the overlying strata was nonlinear, and it decreased with increasing roof height. A support pressure concentration area was formed within a certain range of the stope roof. The numerical simulation results are basically consistent with the similar simulation experimental results.

\section{Introduction}

Among the major phosphate rock-producing countries, China has abundant phosphate rock resources but insufficient production and still needs to import some phosphate rocks. The main reason for this is that construction and production are restricted by the inclined mining method and gently inclined medium-thick ore bodies [1-4]. At present, most mines mainly adopt the shallow hole room-pillar method of underground mining, followed by the pillarless sublevel caving method and the bottom ore structure. However, practice has demonstrated that the room-pillar method of underground mining of medium-thick ore bodies causes a series of problems in rock drilling, ore transportation, and roof management [5-8]. Currently, many valuable studies have been conducted on phosphate filling. Ding et al. analyzed the mechanism of surface subsidence and ground fissures caused by block caving and underground filling based on the law of displacement evolution, and the surface showed obvious segmentation characteristics [9]. Du et al. revealed the basic laws of roof caving and surface subsidence in the process of mining metals via pillarless sublevel caving [10]. Rui proposed that the pillarless sublevel caving method requires the formation of a cover layer with a certain thickness to achieve roof pressure management [11]. Ren proposed that it is more economical to adopt pillarless sublevel caving in open pit-tounderground mining [12]. 
The abovementioned methods cannot effectively verify the experimental results or systematically explain the failure evolution of the stope. With the proficient application of numerical simulation technology to phosphate filling, Xia used FLAC3D (Fast Lagrangian Analysis of Continua 3D) to simulate the specific characteristics of the ore body's structure in the main ore layer and revealed the evolutionary law of ground failure [13]. Wang et al. studied the distribution rate of the abutment pressure based on FLAC3D numerical simulations and proposed that retaining the coal safety pillar used to protect the inclination angle can increase the coal utilization rate [14]. Li et al. used the pillarless sublevel caving method to analyze the movement of pillars and pointed out the importance of optimizing the oredrawing step based on the PFC3D (Particle Flow Code 3D) particle flow results [15].

In general, these methods have not been used to systematically study the destruction and evolution laws of inclined and gently inclined medium-thick ore bodies. In addition, they cannot take into account the economic benefits and result in the waste of recycled ore. Therefore, based on the geological conditions and mining technology of the No. 6 pit in the eastern mining area of the Jinning phosphate mine, we propose an improved pillarless sublevel caving method. This method reduces the ridge loss and improves the mining recovery rate. Based on similar physical model experiments and universal distinct element code (UDEC) numerical simulations, the evolution of the displacement and the failure of the overlying strata were obtained.

\section{Similar Physical Model Experiments}

2.1. Engineering Background. The No.6 pit in the eastern mining area of the Jinning Phosphate Mine is located in the hinterland of the Yunnan Plateau, China. It belongs to the Jinsha River system and is adjacent to the Nanpan River watershed in the south. This mine trends in the north-south direction, with a maximum elevation of $2483.5 \mathrm{~m}$. The area has a subtropical monsoon climate, and the maximum annual rainfall is $1172.1 \mathrm{~mm}$. The rainy season is mainly concentrated from May to October, accounting for $80 \%$ of the annual precipitation. There are no surface water bodies in the mining area except for small scattered reservoirs that intercept the streams in the foothills. The mining area is close to the middle section of the western wing of the Wangjiawan syncline, which is a monoclinic structure that strikes nearly north-south and dips eastward. The stratigraphic occurrence in the region strikes $335-355^{\circ}$ to the north of Wangjiawan with an inclination angle of $40-50^{\circ}$ and strikes $350-10^{\circ}$ to the south of Wangjiawan with an inclination angle of $20-30^{\circ}$. The structure in the monoclinic area is relatively simple, and the secondary folds are not fully developed (Figure 1).

2.2. Similarity Criterion and Parameters. The transfer of phosphate ore from open pit-to-underground mining is a complex engineering system involving many factors [16]. In the similar simulation tests, we mainly considered the following parameters: the thickness of the phosphate rock layer $M$, the thickness of each rock layer $H$, the compressive strength $\sigma_{c}$, the tensile strength $\sigma_{t}$, the bulk density $\gamma$, the elastic modulus $E$, the time $t$, and Poisson's ratio $\mu$. The equation is

$$
F\left(H, M, \sigma_{c}, \sigma_{t}, \gamma, E, \mu, t\right)=0 .
$$

The following five similar criteria can be obtained by applying the dimensional analysis method:

$$
\left\{\begin{array}{l}
\pi_{1}=\frac{\sqrt{H}}{t}, \\
\pi_{2}=\frac{E}{\sigma_{c}}, \\
\pi_{3}=\frac{\sigma_{c}}{\sigma_{t}}, \\
\pi_{4}=\frac{\gamma H}{\sigma_{c}}, \\
\pi_{5}=\frac{M}{H} .
\end{array}\right.
$$

Therefore, in order to make the model similar to the prototype, it needs to satisfy the following equations:

$$
\begin{aligned}
\frac{E_{m}}{E_{p}} & =\frac{\sigma_{t m}}{\sigma_{t p}}, \\
\frac{\sigma_{c m}}{\sigma_{c p}} & =\frac{\sigma_{t m}}{\sigma_{t p}}, \\
\frac{\sigma_{c m}}{\sigma_{c p}} & =\frac{\gamma_{m} \cdot H_{m}}{\gamma_{p} \cdot H_{p}}, \\
\frac{H_{m}}{H_{p}} & =\frac{M_{m}}{M_{p}}, \\
\frac{t_{m}}{t_{p}} & =\sqrt{\frac{H_{m}}{H_{p}}} .
\end{aligned}
$$

Based on the laboratory conditions, we conducted experiments on a rigid $3.0 \mathrm{~m} \times 0.30 \mathrm{~m} \times 2.0 \mathrm{~m}$ (length $\times$ width $\times$ height) model frame. The model design parameters are presented in Table 1 .

2.3. Similar Material. In the experiment, we used fine river sands as the aggregates, calcium carbonate and gypsum as the cementing materials, and sodium tetraborate (boric acid) as the retarder [17-21]. The larger structural surfaces (faults) in the actual site were individually simulated by adding various additives (rosin, wood powder). The layer simulation method is to screen a mica powder and grease medium as the interlayer spacers on the layer's surface. The detailed proportioning steps are as follows: 


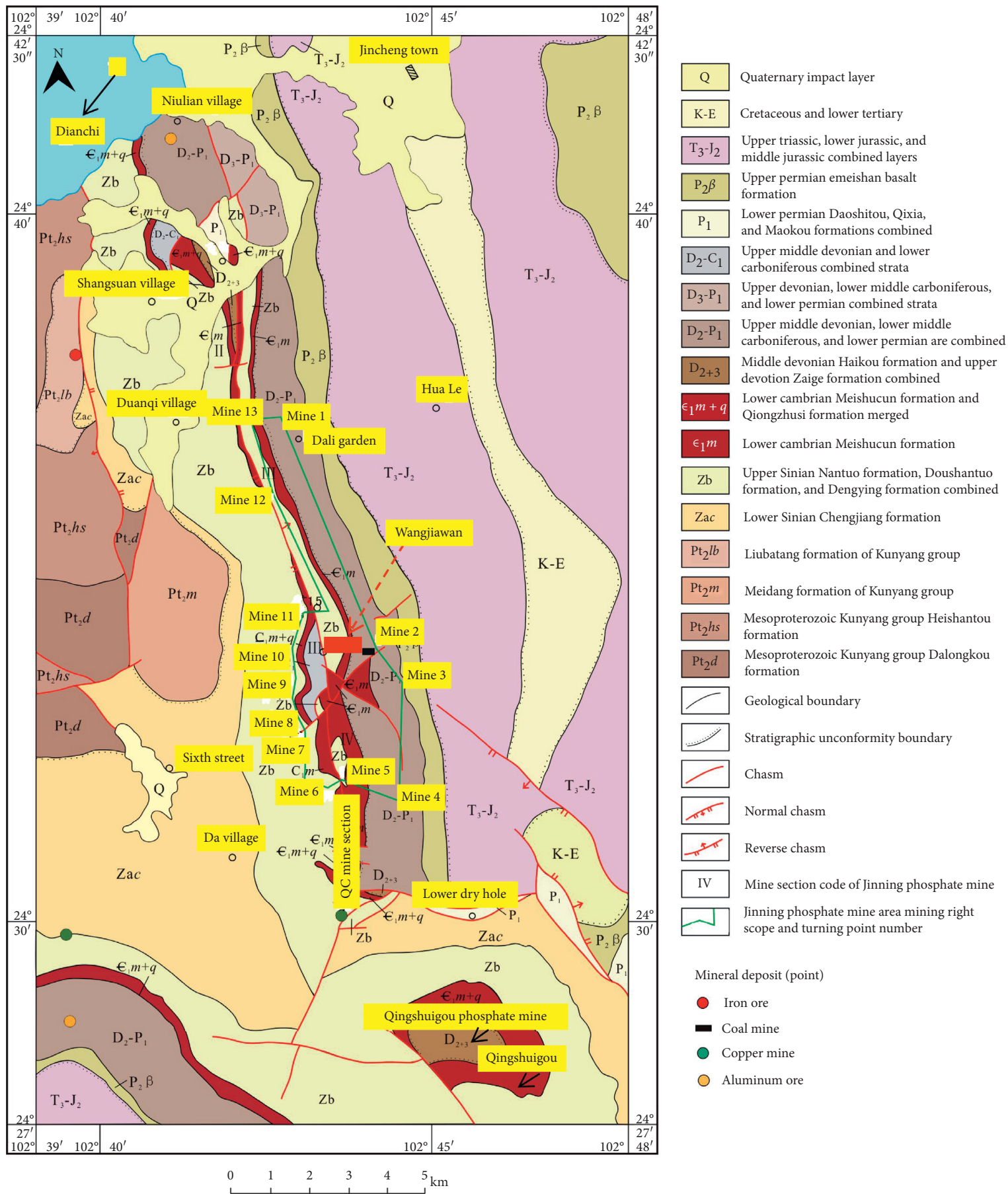

Figure 1: Regional geologic map of the Jinning phosphate mine.

(1) Brush the test mold with engine oil

(2) Weigh the sand, gypsum, and calcium carbonate in a certain proportion, mix, and stir evenly

(3) Add a certain amount of water containing borax, stir, and pour into the mold

(4) After drying for about four days, place the finished test piece $(10 \mathrm{~cm} \times 5 \mathrm{~cm} \times 5 \mathrm{~cm}$ standard cylindrical test piece) on the servo pressure testing machine to measure its uniaxial compressive strength (Figure 2)
In order to reduce the error generated in the material proportioning process, we took the average value of the compressive strength of the three test pieces as the compressive strength of the material ratio number $[22,23]$. The proportioning of the model similar material of the No. 6 pit in the eastern mining area is shown in Table 2.

2.4. Physical Model Making Process. First, we applied engine oil to the surface of the template. Then, we weighed the required sand, calcium carbonate, and gypsum and poured 
TABLE 1: The parameter table of the model design.

\begin{tabular}{lc}
\hline Parameters & Numerical values \\
\hline Model size ratio & $1 / 240$ \\
Model length $(\mathrm{mm})$ & 3000 \\
Model height $(\mathrm{mm})$ & 1040 \\
Model width $(\mathrm{mm})$ & 300 \\
Time similarity coefficient & $1 / 16$ \\
Bulk weight similarity coefficient & 0.81 \\
Intensity similarity coefficient & $1 / 296$ \\
External force similarity coefficient & $5.86 \times 10^{-8}$ \\
Modulus of elasticity & $1 / 296$ \\
Poisson's ratio & 1 \\
\hline
\end{tabular}

them into the mixer to mix. We added a certain amount of retarder (borax) and water to the mixed material and mixed it evenly. The prepared material was poured into the model frame and was smoothed and compacted with a spatula. The template was placed on its side, and the material was poured. This process was repeated several times until the designed height of the physical model was reached. After drying for one week, we removed the template on both sides, continued to dry the sample for two weeks, and finally carried out the mining and observation experiments. During the production process, we used mica powder to separate the layers from each other. The actual physical model is shown in Figure 3.

\section{Method}

3.1. Improved Pillarless Sublevel Caving Method. The pillarless sublevel caving method is mainly suitable for steeply inclined ore bodies with a medium or greater thickness, as well as inclined and gently inclined extremely thick ore bodies [24-27]. For moderately thick and gently inclined phosphate ore, this method will result in the loss of a large amount of ore. Therefore, we propose an improved pillarless sublevel caving method. This method is a new mining scheme in which a recycling route is added at the bottom, which greatly reduces the cost of filling (Figure 4(a)). Our method utilizes the space provided by the first segmented approach to induce natural falling of the surrounding roof rock. By digging the surrounding rock of the footwall to form a recycling route, the ore remaining in the stope can be fully recovered. In order to recover the ridge residue and the bottom wall residue, it is necessary to set up a recovery route in the surrounding rock under the residue. The essence of setting up the recovery route is to use the flow characteristics of the bulk to increase the recovery rate (Figure $4(\mathrm{~b})$ ). The flow of the bulk only occurs in a certain range above the discharge outlet. The calculation formula for this range is

$$
R=2.5 \sqrt{0.5 \beta Z^{\alpha}} .
$$

In equation (4), $R$ is the radius of the bulk flow range; $Z$ is the height coordinate value; and $\alpha$ is the bulk flow parameter.

\subsection{Simulation of Underground Mining and Displacement} Monitoring. An improved pillarless sublevel caving method was used to simulate the mining process in underground mines. As shown in Figure 4(c), the distance between the adjacent mining approach and the recovery route is $11 \mathrm{~m}$ $(4.6 \mathrm{~cm})$. Every time an approach is advanced, the surface and the ground are measured and recorded after an hourlong interval. In the initial stage of mining, we only dug out part of the ore body. After the surrounding rock collapses, the surrounding rock without restriction on both sides will be scattered to the outside of the model. At this time, manual backfilling is required to form an overburden.

\section{Results}

4.1. Collapse Process and Theoretical Analysis of the Overlying Strata. The collapse of the overlying strata is firstly the breaking of roof strata, then the instability of broken rock blocks, and finally directly to the surface cracking and collapse. The process is mainly divided into the following stages.

(1) Stable stage (the first to the second route): after the ore body of the two routes is mined out, the surrounding rock is stable and there is no falling phenomenon.

(2) Falling stage (the third to the fourth route): in this stage, the overlying roof gradually bends and deforms to falling. After the mining of the fourth approach, cracks appear in the overlying strata. About 2 hours later, the gravelly quartz sandstone in the roof partially collapses (Figure 5(a)).

(3) Caving stage (the fifth to the sixth route): with the development of mining, the width of the caving arch gradually increases, the slag falls from the vault, and the cracks continue to develop. At the end of the sixth recovery route, the gravelly quartz sandstone collapses as a whole, and the vault of the roof fall arch shows the phenomenon of bed separation, and more new cracks are produced (Figure 5(b)).

(4) Surface cracking and collapse stage: with the progress of mining, the layer separation phenomenon of falling arch roof intensifies. When the eighth mining approach is completed, the crack development speed is accelerated, tension joints appear on both sides of the model (Figure 6), and the crack length gradually extends downward. Finally, the surrounding rock between the two tension joints falls as a whole, resulting in surface cracking and settlement. In the subsequent excavation process, the crack length further increases, a new tension crack appears outside the initial crack, and the surface subsidence value gradually increases. However, due to the existence of the lower ridge ore body, the surface subsidence is slow and has obvious process. When the ridge is excavated through the mining recovery route, the overburden layer falls with the mining, or even the ore falls ahead of the mining, the overlying surrounding rock collapses faster, the scope expands, and the surface subsides further. 


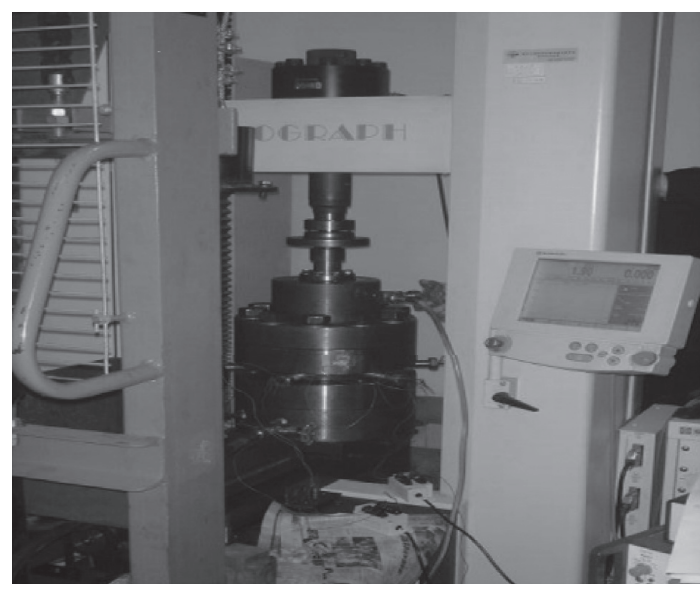

(a)

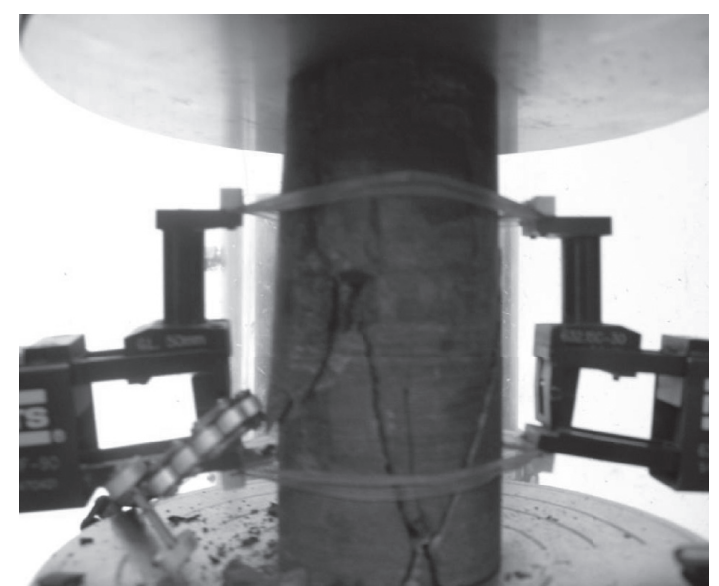

(b)

FIgURE 2: (a) Servo experimental equipment. (b) Typical uniaxial compression failure mode of rock samples.

TABLE 2: The proportioning table of the model similar material of the No.6 east mining area.

\begin{tabular}{|c|c|c|c|c|c|}
\hline Lithology & $\begin{array}{c}\text { Actual } \\
\text { thickness }(\mathrm{m})\end{array}$ & $\begin{array}{l}\text { Actual strength } \\
(\mathrm{MPa})\end{array}$ & $\begin{array}{c}\text { Simulated } \\
\text { thickness }(\mathrm{m})\end{array}$ & $\begin{array}{c}\text { Simulated } \\
\text { strength }(\mathrm{kPa})\end{array}$ & $\begin{array}{l}\text { Similar material ratio } \\
\text { (sand : calcium } \\
\text { carbonate : gypsum) }\end{array}$ \\
\hline Quaternary cover layer & 17.47 & 20.26 & 7.28 & 68.56 & $6: 7: 3$ \\
\hline Gravel dolomite & 59.00 & 95.86 & 24.58 & 323.52 & $3.5: 5: 6$ \\
\hline Layered cryptocrystalline dolomite & 17.00 & 88.32 & 7.08 & 298.85 & $3.8: 5: 5$ \\
\hline Medium to coarse crystalline dolomite & 45.00 & 80.00 & 18.75 & 270.69 & $4: 2: 8$ \\
\hline Layered argillaceous dolomite & 9.00 & 63.62 & 3.75 & 215.27 & $4: 5: 5$ \\
\hline Pebbly quartz sandstone & 17.80 & 88.32 & 7.42 & 298.85 & $3.8: 5: 5$ \\
\hline Industrial phosphate rock & 13.31 & 137.12 & 5.54 & 463.98 & $3: 2: 8$ \\
\hline Low-grade phosphorus rock formation & 21.94 & 118.00 & 9.14 & 399.28 & $3.2: 3: 7$ \\
\hline Medium-thick layered dolomite & 16.00 & 101.88 & 6.67 & 344.73 & $3.5: 3: 7$ \\
\hline Medium-thick primary dolomite & 33.50 & 98.50 & 13.96 & 333.29 & $3.5: 3.5: 6.5$ \\
\hline
\end{tabular}

4.2. Analysis of the Similar Physical Simulation Experiment Results. In the early stage of mining, the overlying rock underwent a small amount of movement (Figure 7(a)). After advancing to the sixth-level mining approach, along with the development of separations and fissures, the quartz sandstone above began to fall off (Figure 7(b)). When the tenthlevel mining approach was excavated, the caving zone of the roof slab expended, and eventually, the old roof ruptured and the ground subsided (Figure $7(\mathrm{c})$ ). During the entire collapse process, the overlying rock strata were first destroyed in the surrounding rock of the goaf and then developed to the deep part of the rock formation, forming an irregular stepped caving zone above the goaf (Figure $7(\mathrm{~d})$ ). In addition, the fissures in the overlying strata continued to develop, and there was obvious layering in the collapse area (Figure 6).

4.3. Overlying Strata and Ground Movement Law. According to the rock displacement monitoring results (Figures 8(a)-8(d)), the subsidence of the overlying rock strata changed dynamically with the advancement of the working face. The subsidence range gradually expanded along the direction of the working face. With the advancement of the mining approach, the lower separation fissures of the overlying strata gradually closed. As the working face advanced, the separation fissures also extended forward and upward. In the case of sufficient mining, after the overlying rock above the ridge sank to the position of the ridge, the sinking speed became very slow or stopped. Therefore, the curve of the lower layer of the surrounding roof rock is wavy, and the closer it is to the roof of the orebody, the greater the difference between the peaks and valleys of the curve (Figure 8(a)). The surface subsidence curve is shown in Figure $8(\mathrm{~d})$. The maximum surface subsidence occurred directly above the phosphorus ore body, and the maximum subsidence displacement gradually moved in the direction of the advancement.

4.4. Stress Variation Law of the Surrounding Rock in the Stope. As shown in Figures 9(a)-9(c), with the advancement of the mining approach, the stress in the overlying strata constantly changed. The stress concentration area affected the rock for about $50 \mathrm{~m}$ in front of the working face, and the peak stress appeared $20 \mathrm{~m}$ in front of the working face. In the process of 


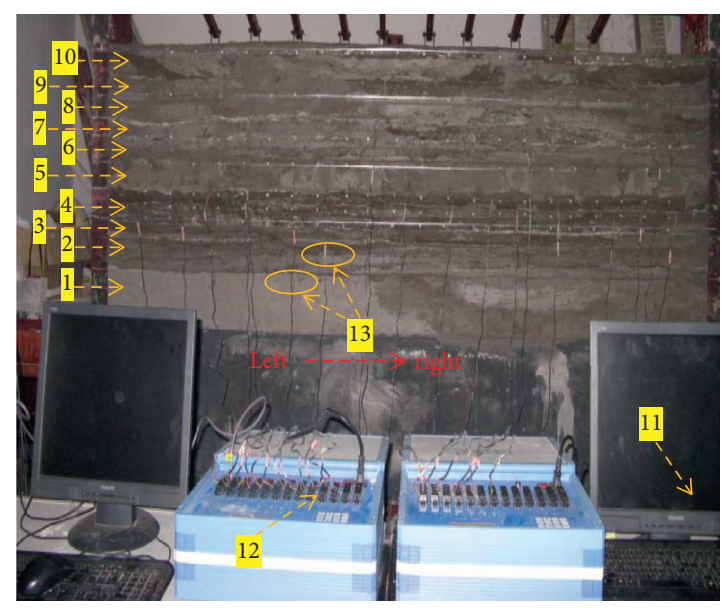

(1) Medium-thick primary dolomite

(2) Medium-thick layered dolomite

(3) Low-grade phosphorous rock formation

(4) Industrial phosphate rock

(5) Pebbly quartz sandstone

(6) Layered argillaceous dolomite

(7) Medium to coarse crystalline dolomite

(8) Layered cryptocrystalline dolomite

(9) Gravel dolomite

(10) Quaternary cover layer

(11) Data acquisition device

(12) Sensor equipment

(13) No. 1-19 displacement sensors position (from left to right)

Figure 3: The actual physical model.

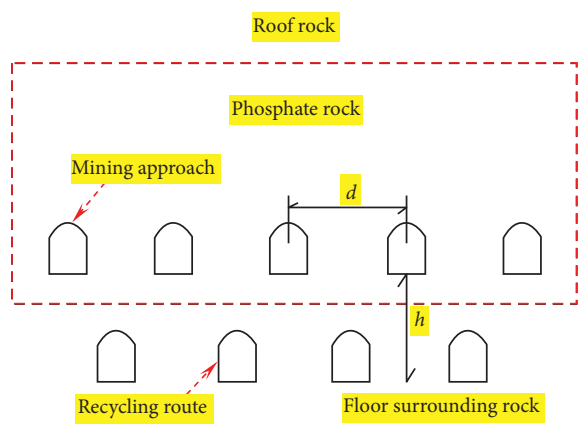

(a)

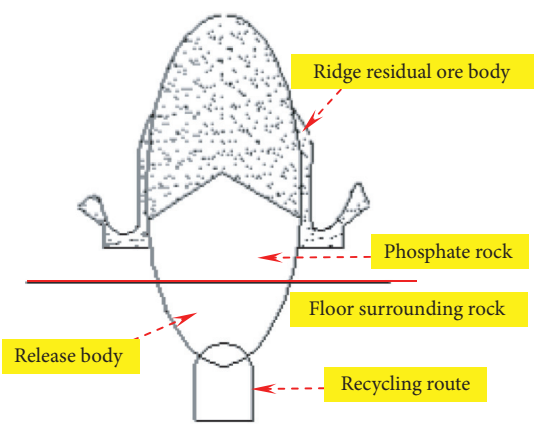

(b)

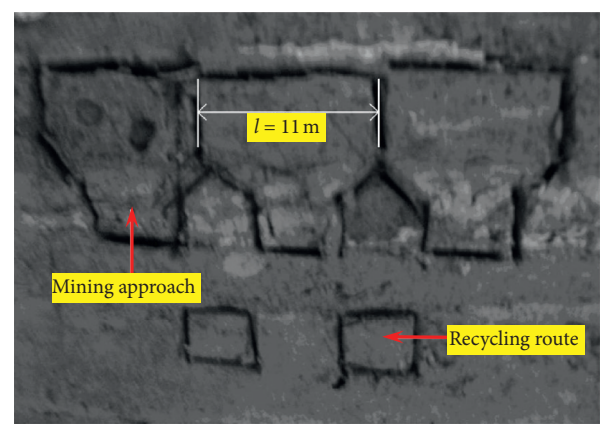

(c)

FIGURE 4: (a) Schematic diagram of the stope structure, (b) schematic diagram of the recovery route, and (c) excavation model diagram. 


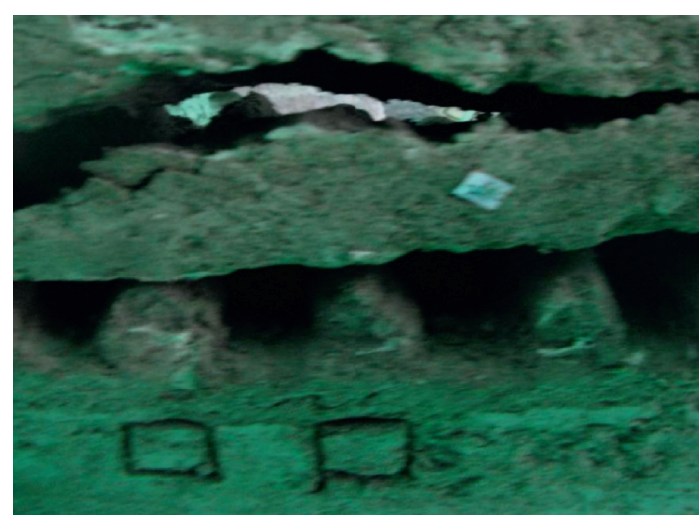

(a)

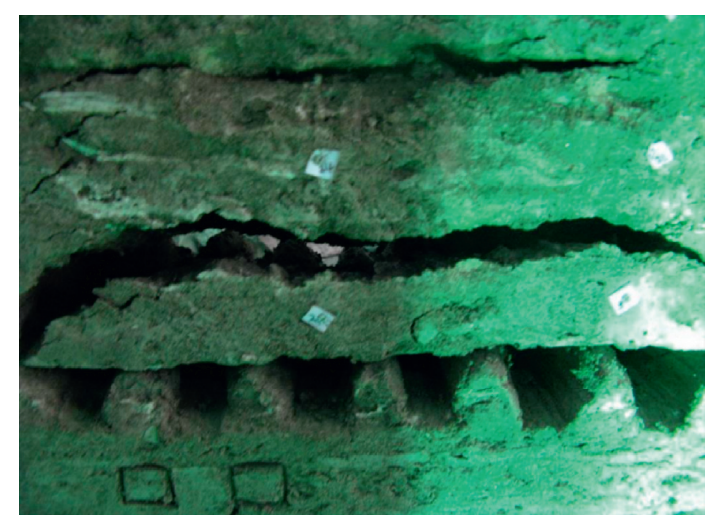

(b)

Figure 5: (a) The roof falling stage; (b) the block caving stage.

excavating and recycling roadways, the stress in the overlying strata of the stope also constantly changed and was more complex (Figures 9(d)-9(f)).

\section{Discussion}

5.1. Size and Boundary Conditions of the Numerical Simulation Model. In the field of mining engineering, UDEC numerical simulation technology has been applied to the static and dynamic analyses of deep underground mining caverns [28-30]. This technology can accurately analyze the fractures and slip induced by the destruction of the surrounding rock of the cavern. Based on the geological conditions and mechanical parameters of the No. 6 pit in the eastern mining area of the Jinning phosphate mine in the Yunnan phosphate group, the thickness of the phosphate rock in the discrete element model was set to $13.31 \mathrm{~m}$. The $X$ direction is the strike direction, and the part of the advancing length of the working face is $720 \mathrm{~m}$. The $Y$ direction has an average burial depth of $250 \mathrm{~m}$. This model simulates a total of 10 layers, and the thickness of each layer is simulated according to the actual thickness (both the $X$ and $Y$ directions consider the 100-meter boundary influential area). Since the mine is an open pit mine (nearly shallowly buried phosphate layer), the strata cannot be omitted in this simulation. The model is $720 \mathrm{~m} \times 250 \mathrm{~m}$ (length $\times$ height) (Figure 10).

The boundary conditions of the calculation model are as follows:

(1) Horizontal boundaries are constraints imposed on the left and right boundaries of the calculation model (the horizontal displacement of the boundary is zero)

(2) The bottom boundary of the calculation model is fixed (both the horizontal and vertical displacements of the bottom boundary are zero)

(3) The top of the calculation model is the free boundary

5.2. Material Constitutive Model and Failure Criterion. In our study, the ideal elastoplastic constitutive model was adopted for the rock mass, and the basic criterion of the rock material failure obeyed the Mohr-Coulomb relationship $[31,32]$. Therefore, the linear failure surface formula corresponding to shear failure is

$$
f_{s}=\sigma_{1}-\sigma_{3} N_{\varphi}+2 c \sqrt{N_{\varphi}} .
$$

In equation (5), $N_{\varphi}=(1+\sin \varphi)(1-\sin \varphi) ; \sigma_{1}$ is the maximum principal stress; $\sigma_{3}$ is the minimum principal stress; $\varphi$ is the angle of internal friction; and $c$ is the cohesion.

If $f_{s}<0$, shear yielding occurs. When the normal stress becomes tensile stress, the Mohr-Coulomb criterion loses its practical significance. For simplicity, however, the yield surface extends to the area where $\sigma_{3}$ is equal to its tensile strength and the tensile strength $\sigma^{t}$. The minimum principal stress cannot exceed the tensile strength:

$$
f_{t}=\sigma_{3}-\sigma^{t}
$$

If $f_{s} \geq 0$, tension yielding occurs. The value that the tensile strength cannot exceed corresponds to the upper limit of the Mohr-Coulomb relationship. The maximum value is determined using the following formula:

$$
\sigma_{\max }^{t}=\frac{c}{\tan \varphi} .
$$

We determined the physical and mechanical parameters of each layer in the model based on the test results. The physical and mechanical parameters of each layer are presented in Table 3.

5.3. Failure Process of Overlying Strata. In the mining process, in order to reflect the evolution of the movement and deformation of the rock layer, step-by-step excavation was adopted [33-38]. We advanced the work surface by a certain distance to perform an operation. When the second-level mining approach was advanced, the overlying strata remained basically unchanged (Figure 11(a)). When the sixth-level mining approach was continued, the gravelly quartz sandstone began to fail under the load of the overlying strata and its own weight (Figure 11(b)). As the advancement continued, the vertical deformation of the 


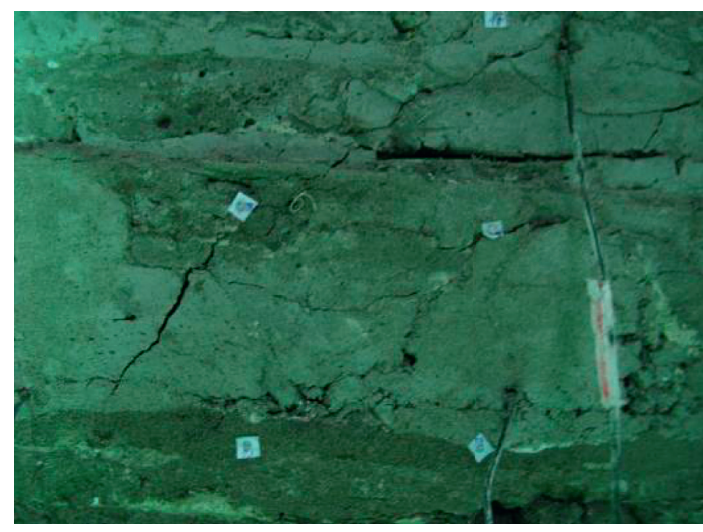

(a)

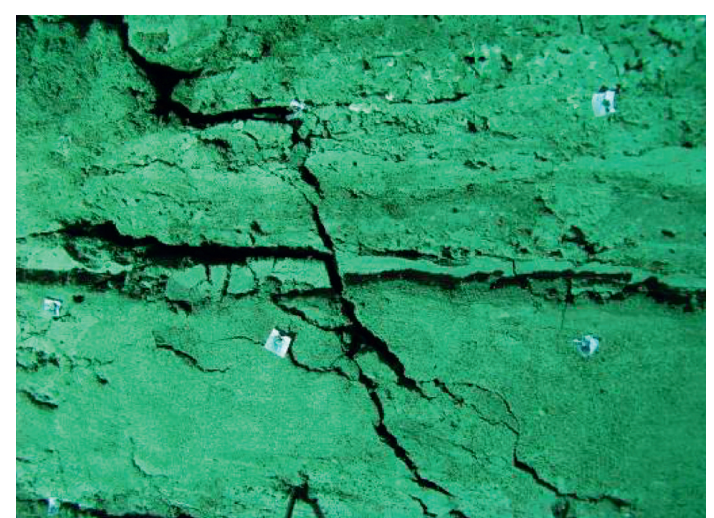

(b)

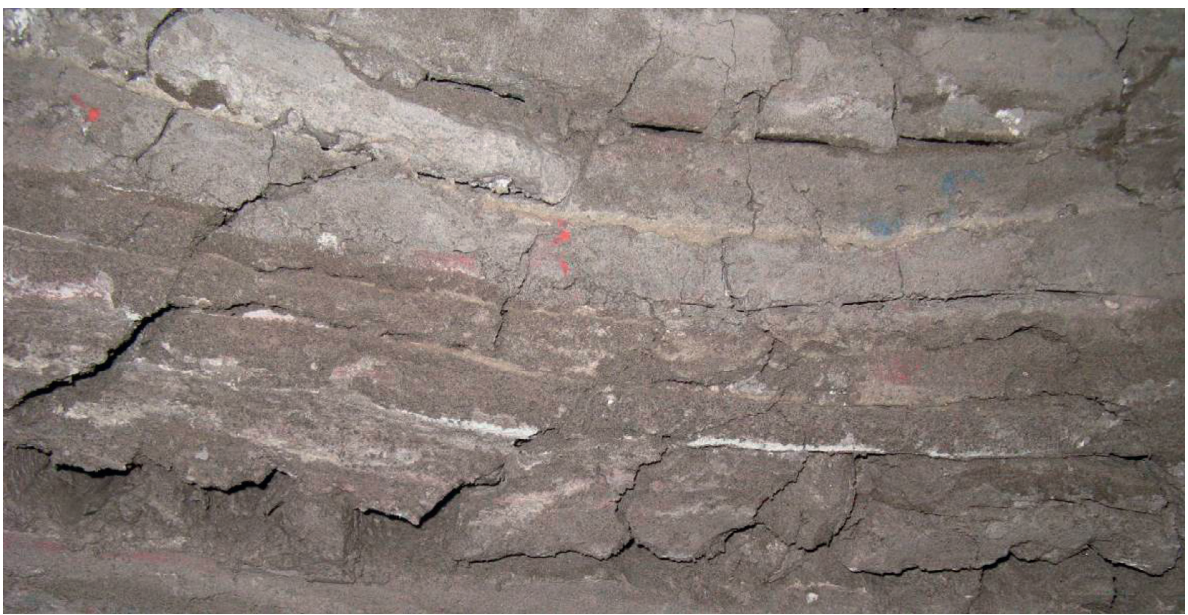

(c)

FIGURE 6: The phenomenon during the experiment. (a) Fissures that develop from the left upwards as the mining approach advances. (b) Fissures that develop form the right upwards as the mining approach advances. (c) Obvious stratification phenomenon during the collapse.

rock formation increased, causing tensile failure and breakage of the rock formation (Figure 11(c)). When the seventeenth-level mining approach was advanced, the broken rock block fell into the goaf, forming a trapezoidal collapse zone (Figure 11(d)). In the process of advancing the first-tenth recovery route, the deformation continued to increase and the old top dolomite cracked (Figures 12(a)$12(\mathrm{c}))$. When the sixteenth-level recovery route ended, the surface began to collapse, and the roof of the overlying rock was the most severely damaged $[39,40]$.

5.4. Displacement of the Overlying Strata. As shown in Figure 13, in the early stage of mining, the upper rock layer was less affected by the mining, and the vertical displacement was small. As the working face advanced, the area of the overlying rock strata affected by the mining continued to increase, and the subsidence value gradually increased. After the overlying rock above the ridge sank to the position of the ridge, the sinking speed became very slow or stopped, so the curve of the lower layer of the roof surrounding rock is wavy. The shorter the distance between the overlying strata and the roof of the orebody, the greater the difference between the peaks and troughs of the curve. The closer it is to the phosphate rock layer, the wider the impact range and the greater the sinking value.

5.5. Variation Law of the Abutment Pressure of the Overlying Strata in the Stope. According to the results of the excavation using the simulated mining approach (Figures 14(a)-14(d)), the supporting pressure gradually stabilized as the working face advanced, and the peak value appeared at $20 \mathrm{~m}$. The area affected by the mining in front of the working face was divided into three parts: (1) the areas severely affected by the mining (within $20 \mathrm{~m}$ ); (2) the areas affected by the mining (within $60 \mathrm{~m}$ ); and (3) the areas unaffected by the mining (beyond $60 \mathrm{~m}$ ). The simulation results of the excavation of the recovery route show that the stress in front of the working face increased, and it constantly changed and became more complicated with the advancement of the recovery route (Figures 14(e)-14(h)).

The numerical simulation results are basically the same as the similar simulation experimental results. This is mainly 


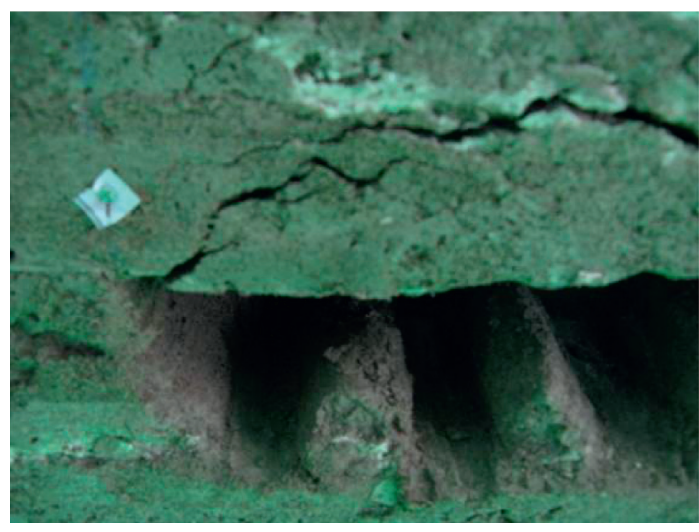

(a)

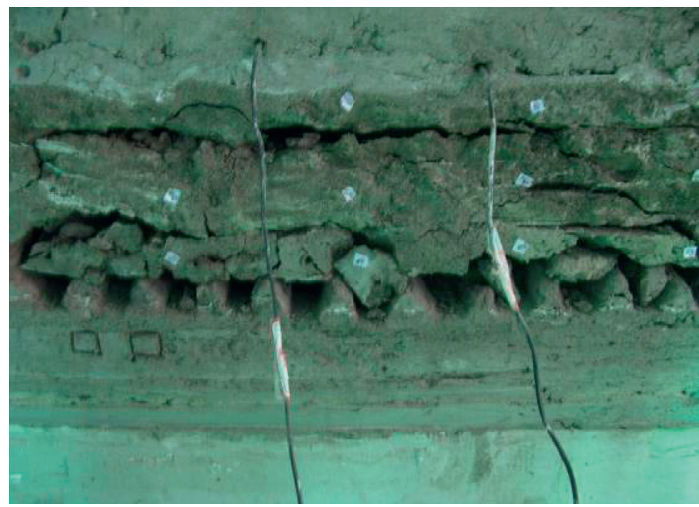

(c)

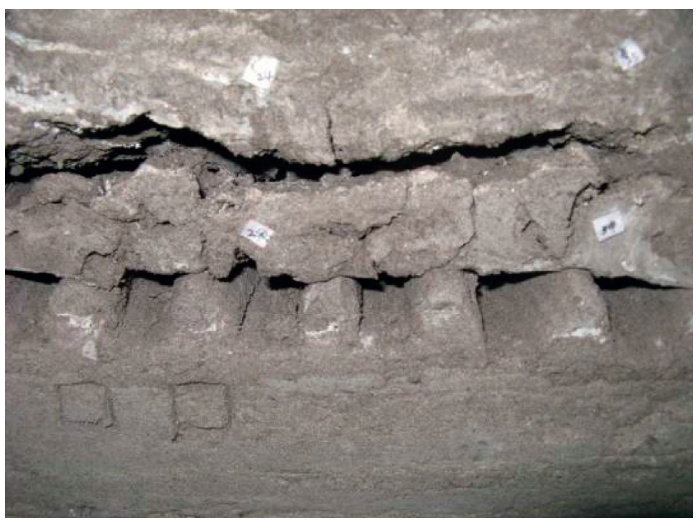

(b)

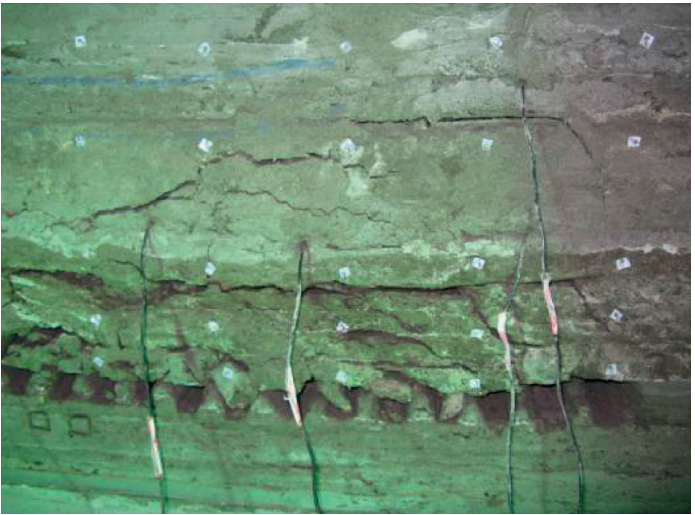

(d)

Figure 7: (a) Fissures appeared in the rock strata of the third-level mining approach. (b) Promotion of the sixth-level mining approach directly above the avalanche. (c) Promotion of the collapse of the top slab of the tenth-level mining approach. (d) The roof collapses after the mining is completed.

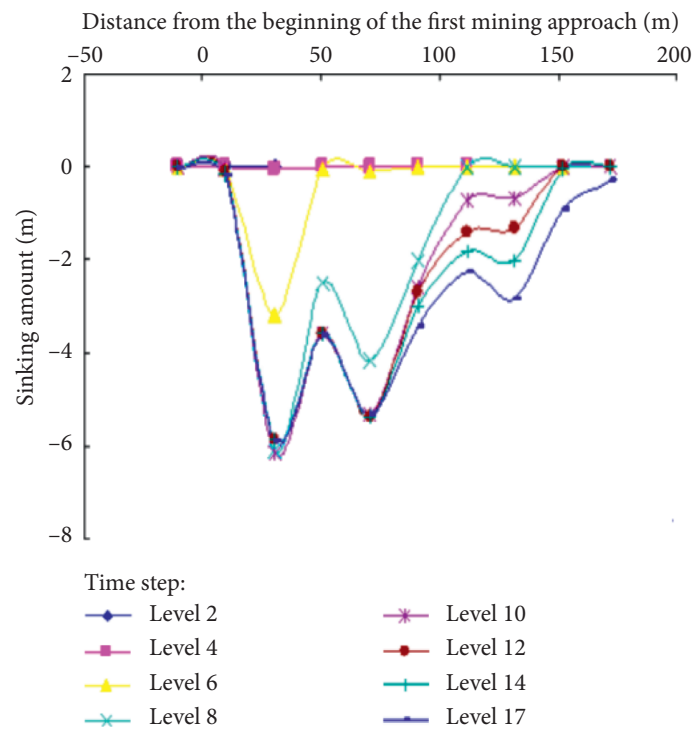

(a)

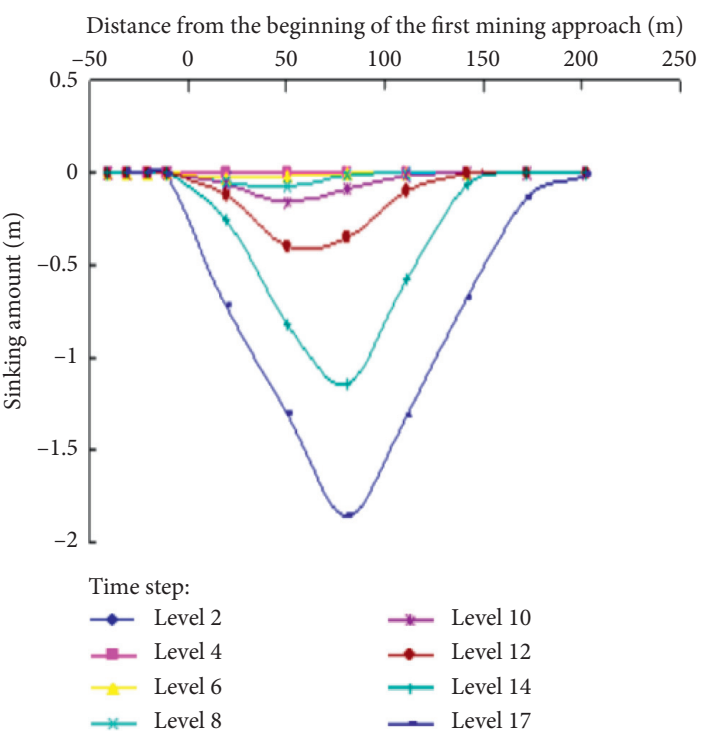

(b)

Figure 8: Continued. 


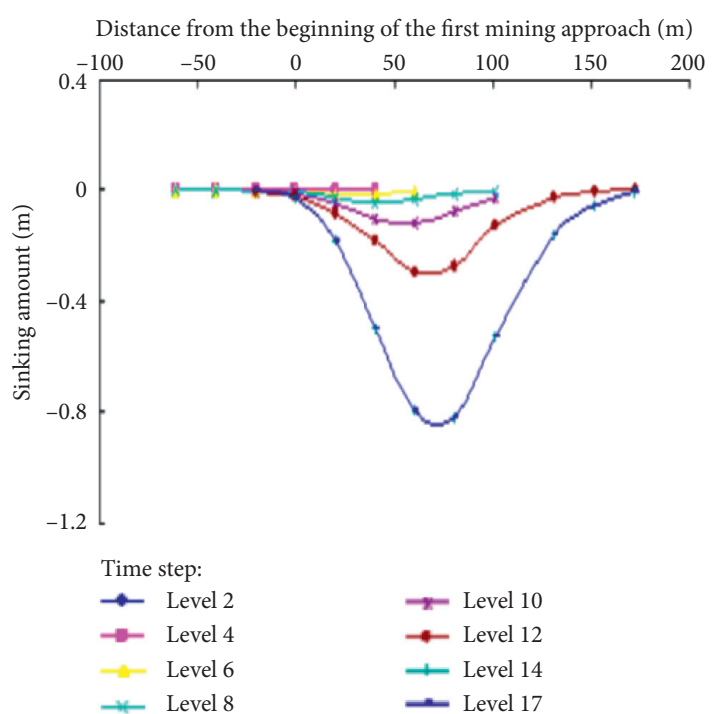

(c)

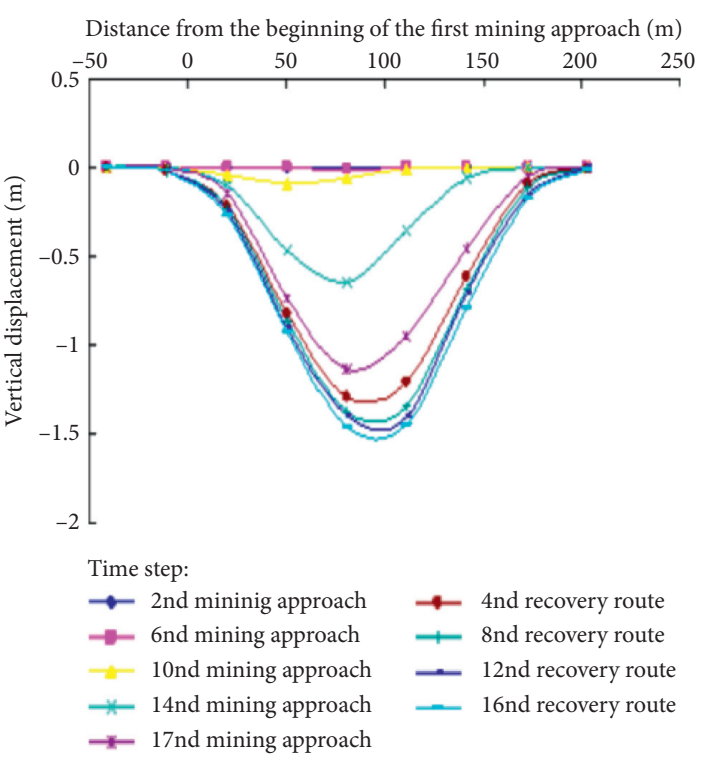

(d)

Figure 8: (a) The subsidence change curve of the rock formation (the second-level measuring points); (b) the subsidence change curve of the rock formation (the fourth-level measuring points); (c) the subsidence change curve of the rock formation (the seventh-level measuring points); and (d) the change curve of the surface subsidence and displacement (advancement via different approaches).

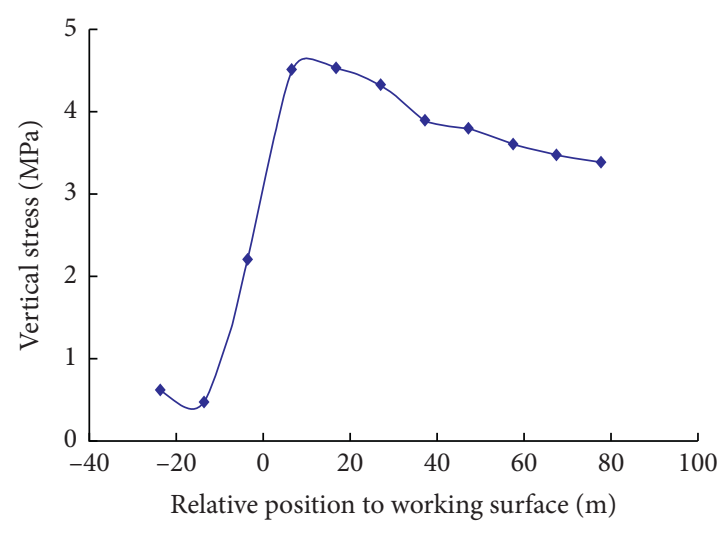

Distance from top plate:

$\rightarrow 12 \mathrm{~m}$

(a)

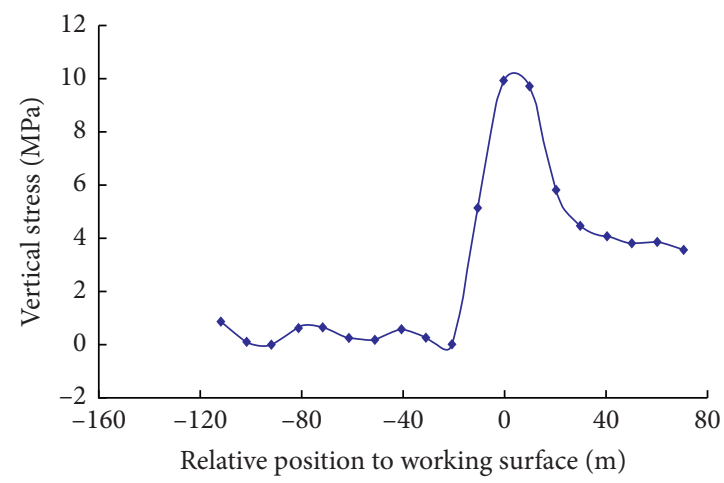

Distance from top plate:

$\rightarrow 12 \mathrm{~m}$

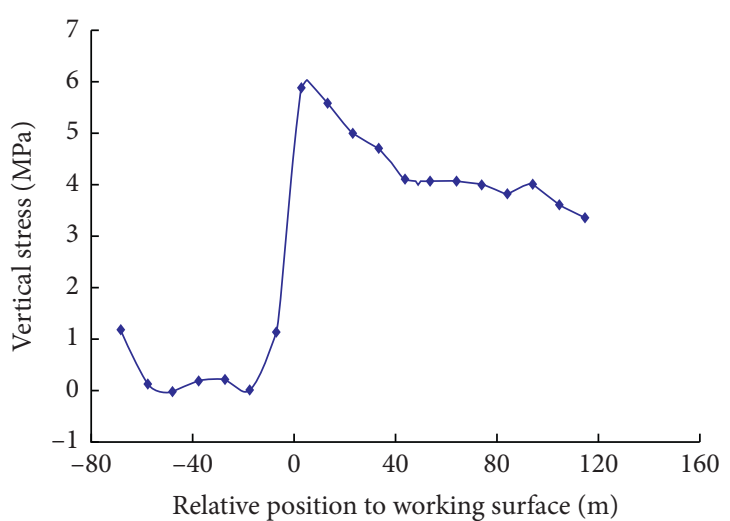

Distance from top plate:

$\rightarrow 12 \mathrm{~m}$

(b)

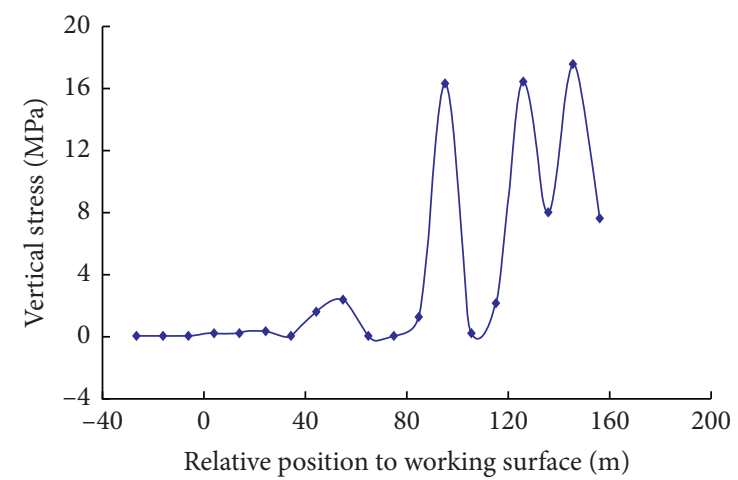

Distance from top plate:

$\rightarrow 12 \mathrm{~m}$

(c)

Figure 9: Continued. 


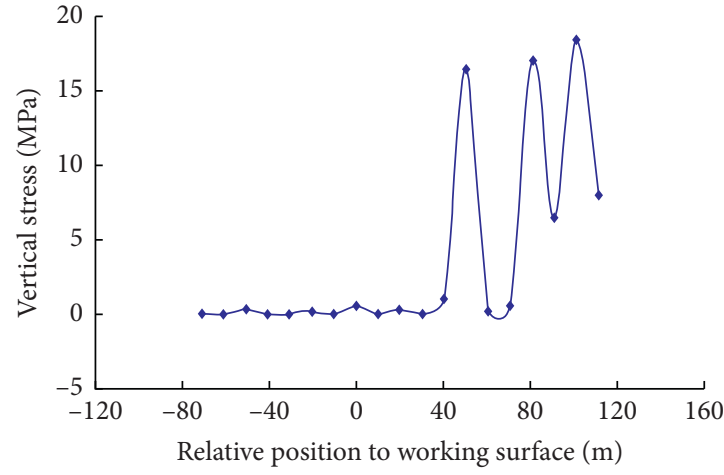

Distance from top plate: $\rightarrow 12 \mathrm{~m}$

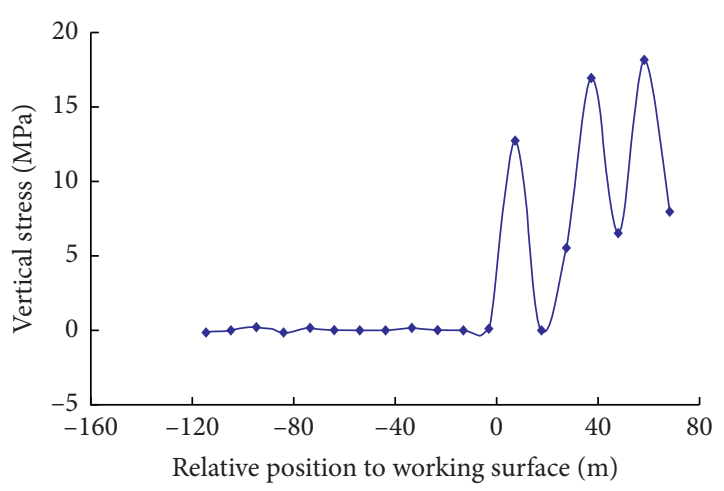

Distance from top plate: $\rightarrow 12 \mathrm{~m}$

(e)

(f)

FiguRE 9: (a) The stress distribution diagram of the fourth-level mining approach; (b) the stress distribution diagram of the eighth-level mining approach; (c) the stress distribution diagram of the twelfth-level mining approach; (d) the stress distribution diagram of the fourthlevel recovery route; (e) the stress distribution diagram of the eighth-level recovery route; and (f) the stress distribution diagram of the twelfth-level recovery route.

TABLE 3: The physical and mechanical properties of the rock.

\begin{tabular}{|c|c|c|c|c|c|c|}
\hline Geotechnical type & $\begin{array}{c}\text { Uniaxial } \\
\text { compressive } \\
\text { strength }(\mathrm{MPa})\end{array}$ & $\begin{array}{c}\text { Uniaxial } \\
\text { tensile } \\
\text { strength }(\mathrm{MPa})\end{array}$ & $\begin{array}{c}\text { Cohesion } \\
(\mathrm{MPa})\end{array}$ & $\begin{array}{l}\text { Internal } \\
\text { friction } \\
\text { angle }\left(^{\circ}\right)\end{array}$ & $\begin{array}{l}\text { Poisson's } \\
\text { ratio }\end{array}$ & Density $\left(\mathrm{kg} / \mathrm{m}^{3}\right)$ \\
\hline Topsoil & $* 13.32$ & ${ }^{*} 0.13$ & $* 0.95$ & $* 40.00$ & $* 0.11$ & 1800 \\
\hline Layered cryptocrystalline dolomite & 18.17 & 1.04 & $* 5.00$ & *42.50 & $* 0.38$ & 2580 \\
\hline Medium to coarse crystalline dolomite & 28.20 & 2.26 & $* 7.24$ & $* 44.20$ & ${ }^{*} 0.30$ & 2610 \\
\hline Layered argillaceous dolomite & 28.02 & 3.13 & *5.76 & $* 44.20$ & $* 0.25$ & 2580 \\
\hline Pebbly quartz sandstone & 52.99 & 2.20 & $* 3.10$ & $* 43.68$ & $* 0.27$ & 2620 \\
\hline Industrial phosphate rock & 82.27 & 6.67 & 10.78 & $* 43.40$ & ${ }^{*} 0.20$ & 2660 \\
\hline Low-grade phosphate rock & 70.80 & 4.38 & $* 9.44$ & $* 43.60$ & $* 0.20$ & 2566 \\
\hline Off-white medium-layered dolomite & 50.50 & 3.07 & $* 9.06$ & $* 60.00$ & ${ }^{*} 0.33$ & 2500 \\
\hline Primary medium-thick layered dolomite & 59.10 & 3.29 & $* 9.07$ & $* 41.26$ & $* 0.23$ & 2624 \\
\hline
\end{tabular}

*Engineering analog data.

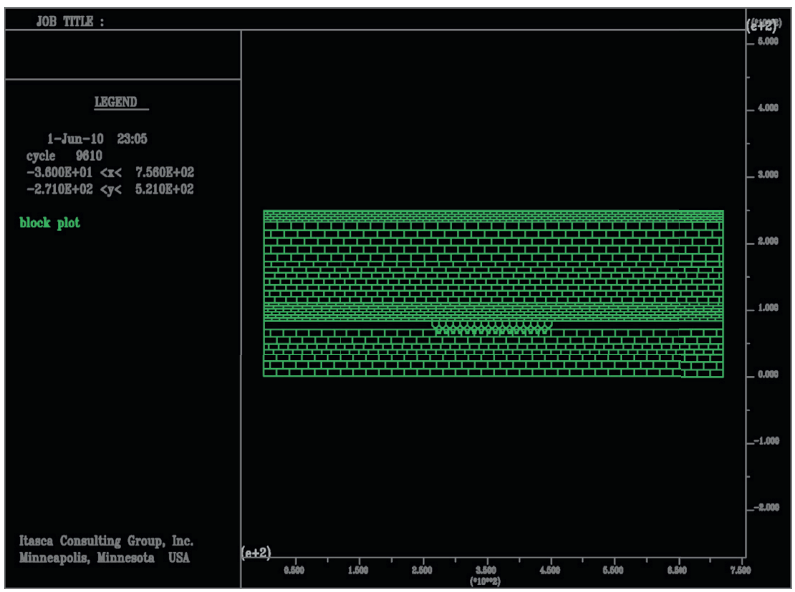

Figure 10: The numerical simulation model.

manifested as (1) the deformation and failure of the overlying rock strata started directly from the roof of the goaf. Then, they gradually developed toward the deep rock formation and collapsed. With the continuous advancement of the mining approach and the recovery route, an irregular trapezoidal collapse zone finally formed in the roof above the 


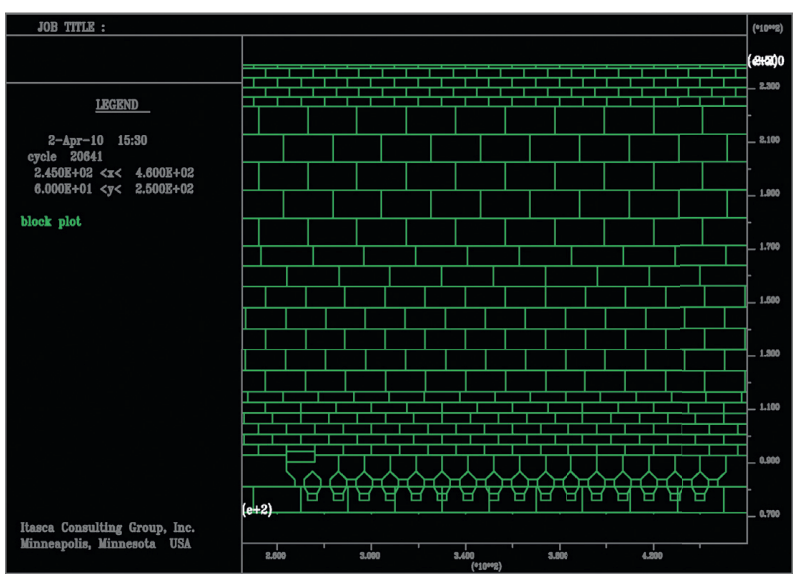

(a)

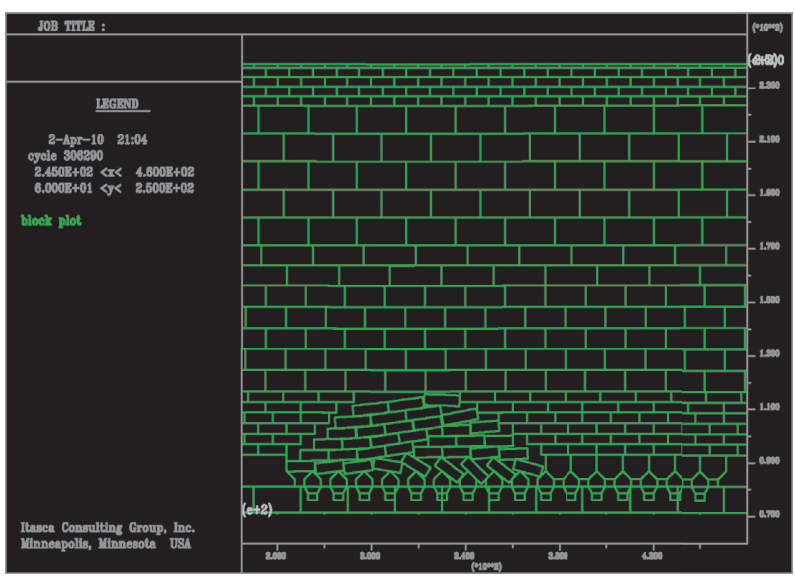

(c)

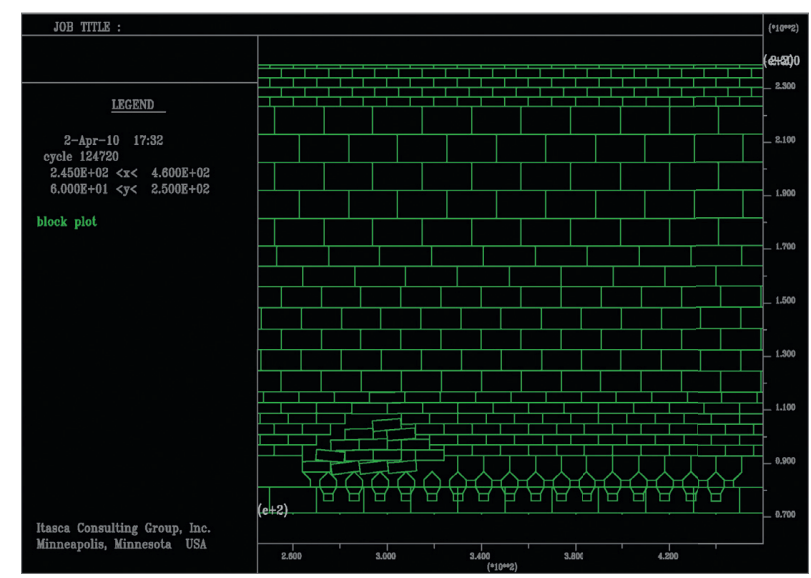

(b)

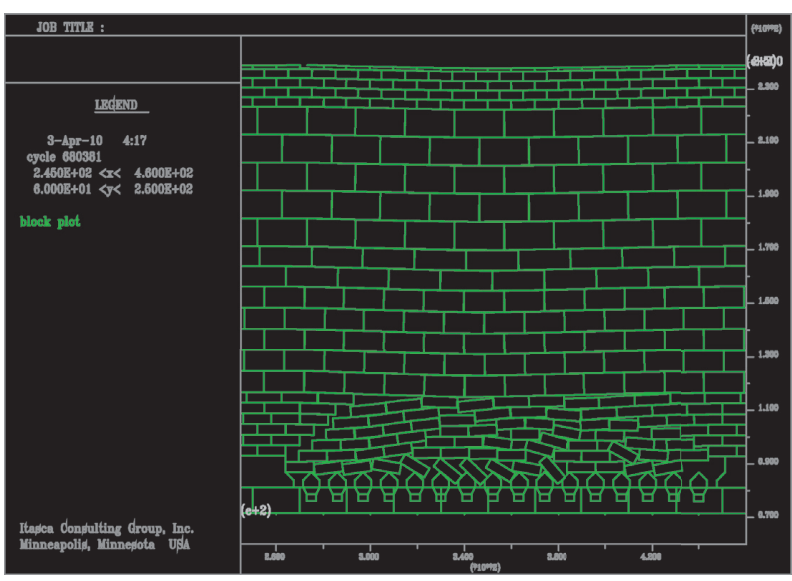

(d)

FIGURE 11: Roof failure process: (a) promotion of the second-level mining approach; (b) promotion of the sixth-level mining approach; (c) promotion of the tenth-level mining approach; and (d) promotion of the seventeenth-level mining approach.

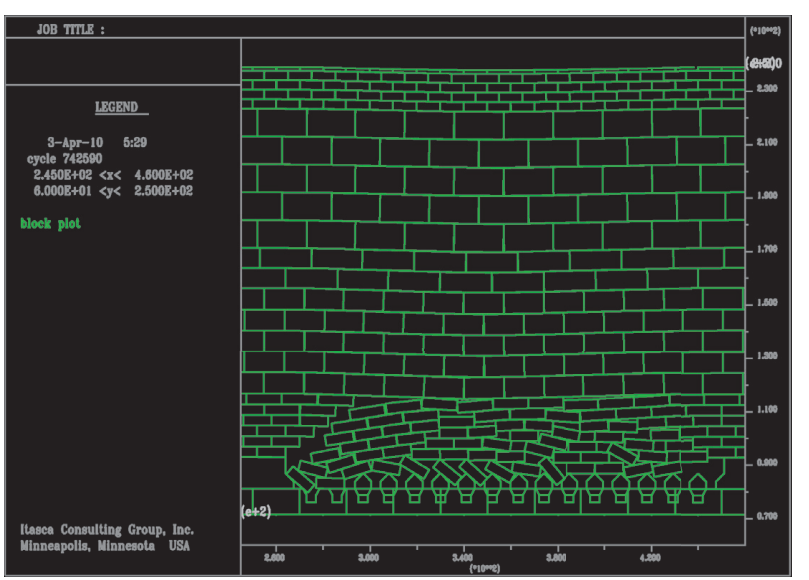

(a)

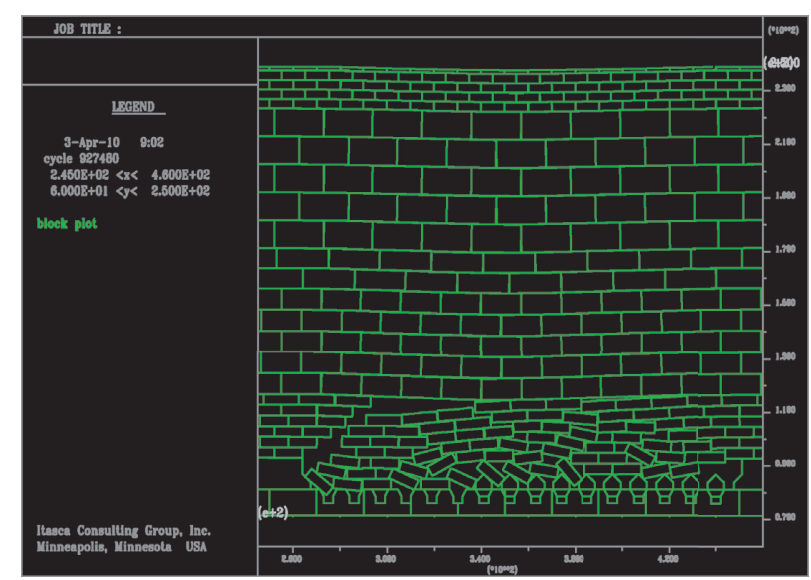

(b)

FIGURE 12: Continued. 


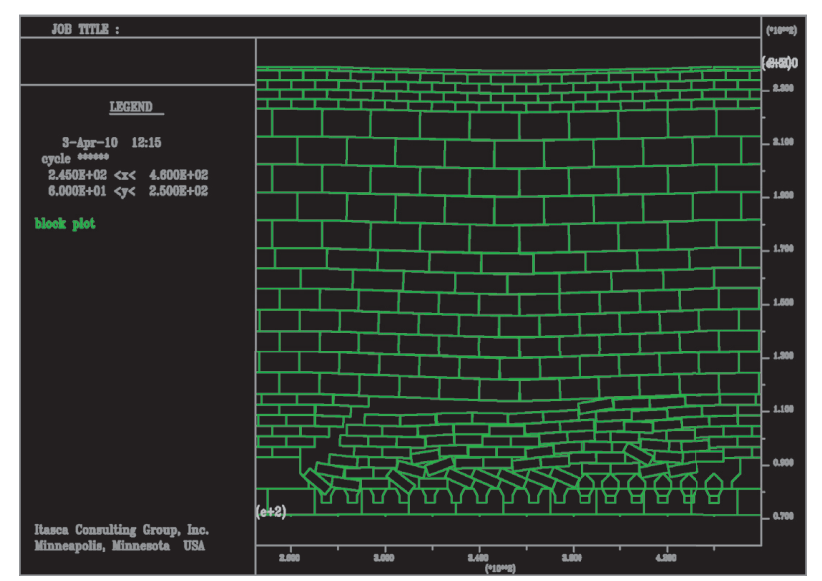

(c)

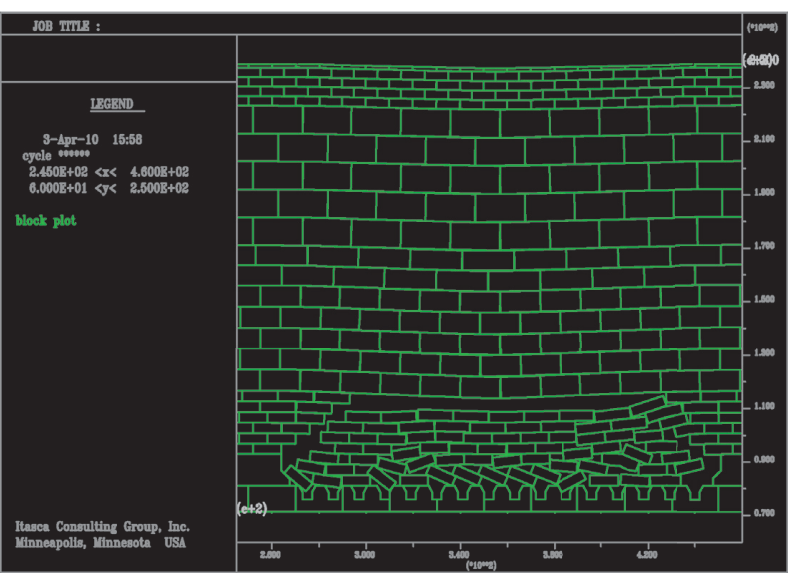

(d)

FIGURE 12: Roof failure process: (a) promotion of the second-level recycling route; (b) promotion of the sixth-level recycling route; (c) promotion of the tenth-level recycling route; and (d) promotion of the sixteenth-level recycling route.

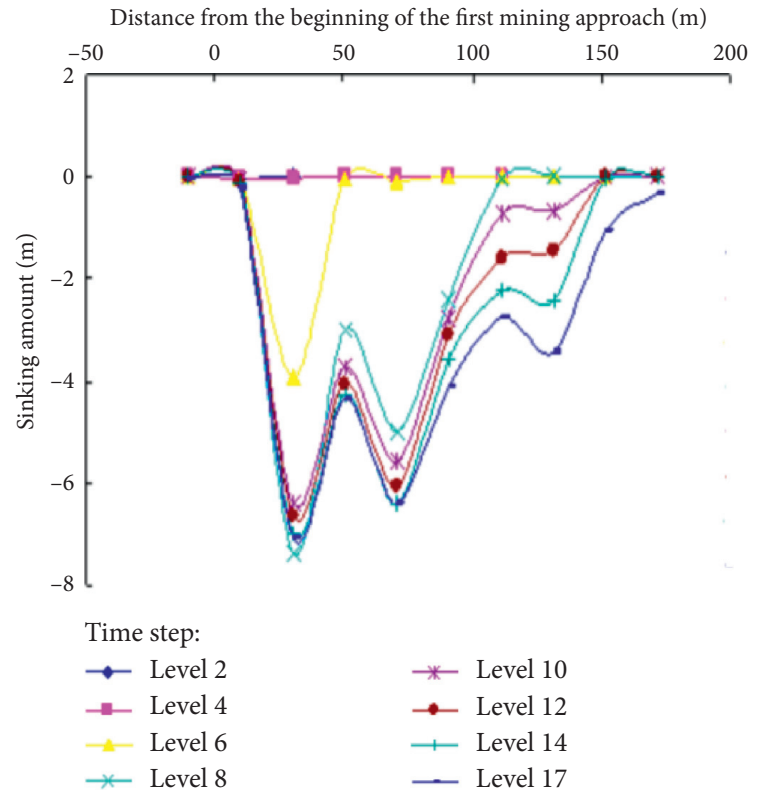

(a)

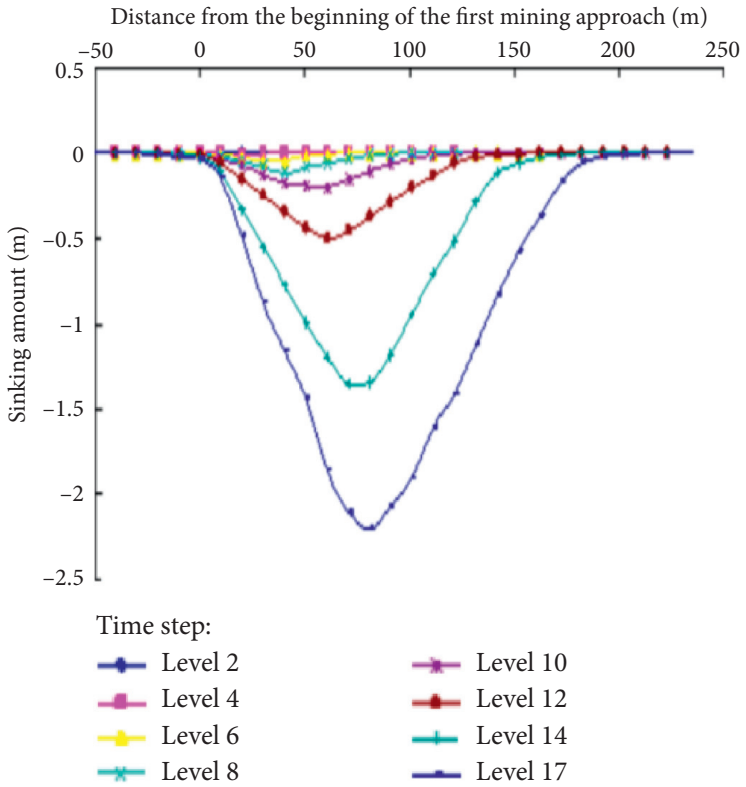

(b)

FIGURE 13: Continued. 


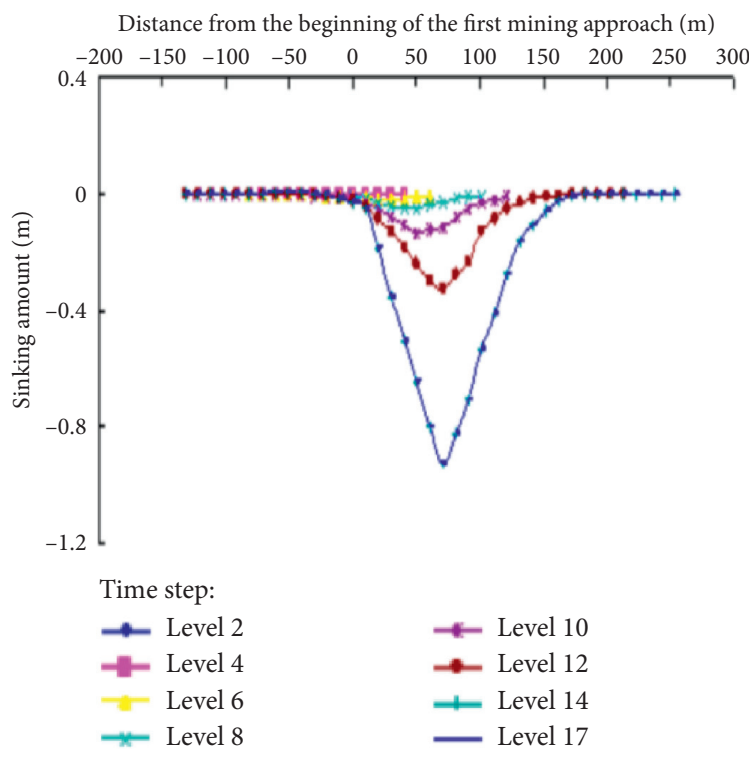

(c)

Figure 13: (a) Subsidence change curve of the rock formation (the second layer measuring points); (b) subsidence change curve of the rock formation (the fourth layer measuring points); and (c) subsidence change curve of the rock formation (the seventh layer measuring points).

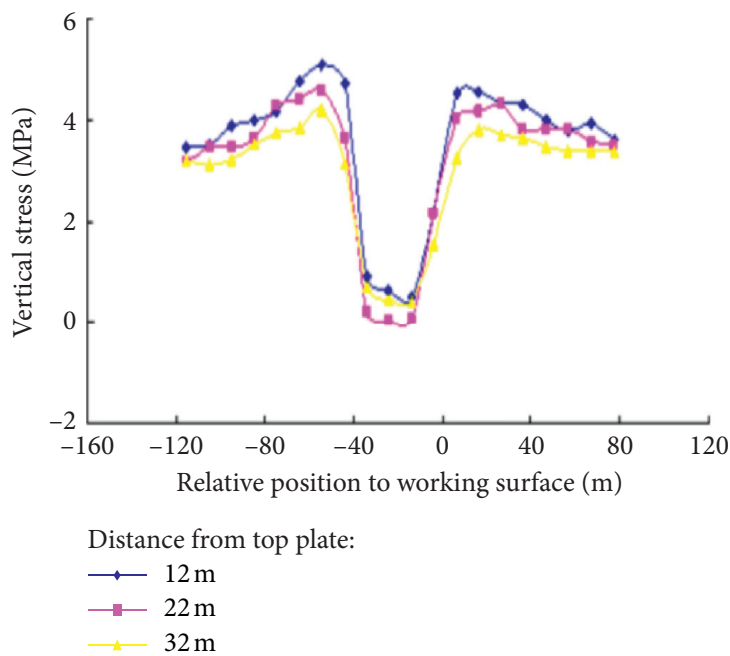

(a)

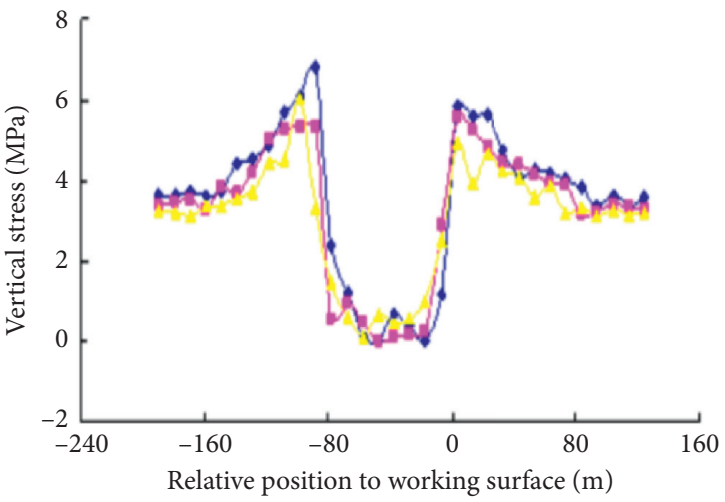

Distance from top plate:

$$
\begin{aligned}
& \longrightarrow 12 \mathrm{~m} \\
& \longrightarrow 22 \mathrm{~m} \\
& \square \quad 32 \mathrm{~m}
\end{aligned}
$$

(b)

FIgURe 14: Continued. 

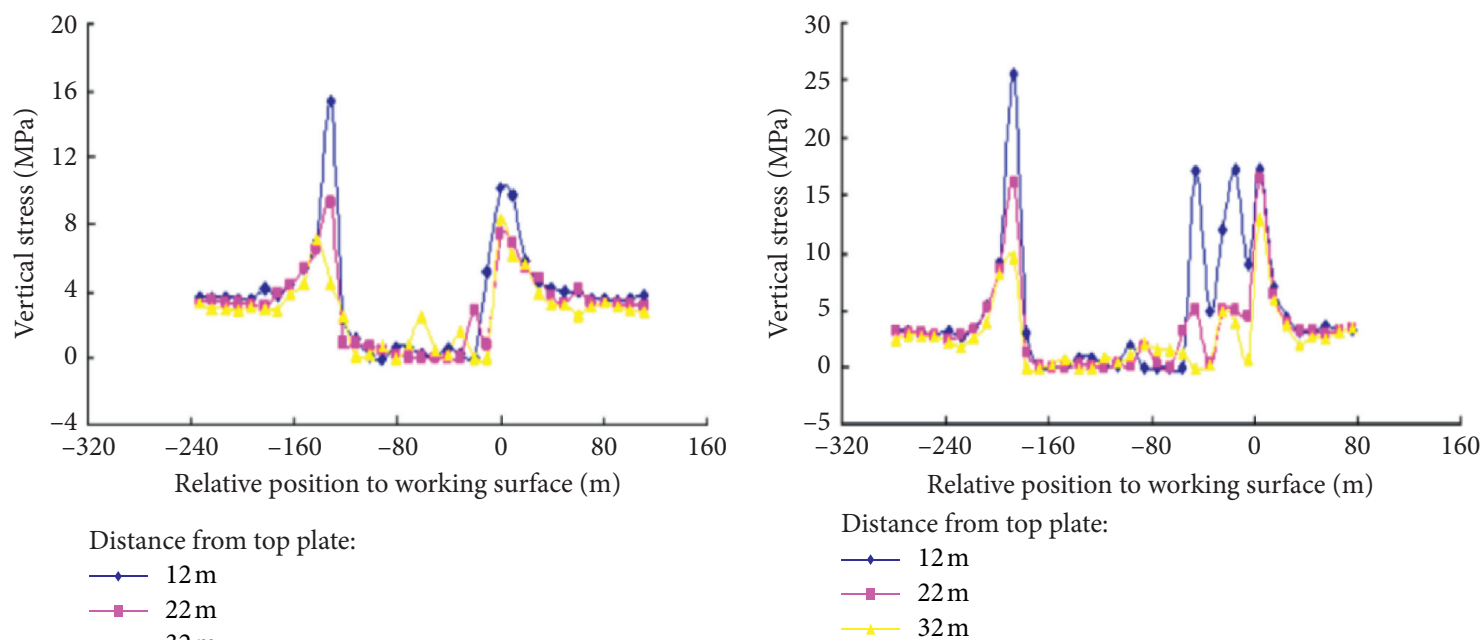

(c)

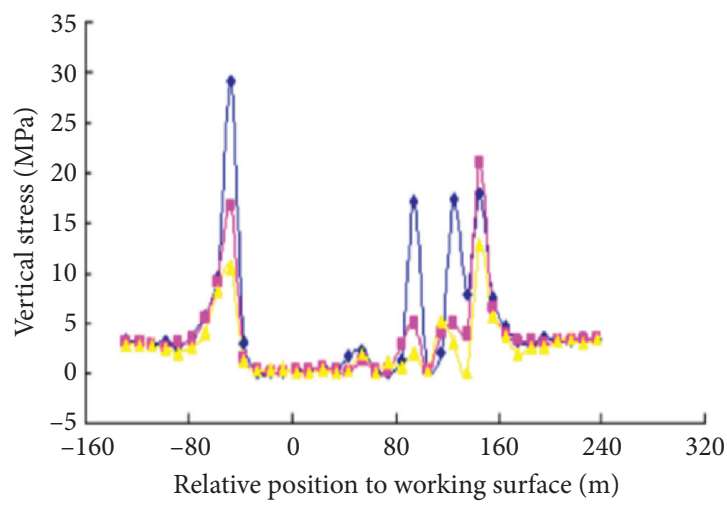

(d)
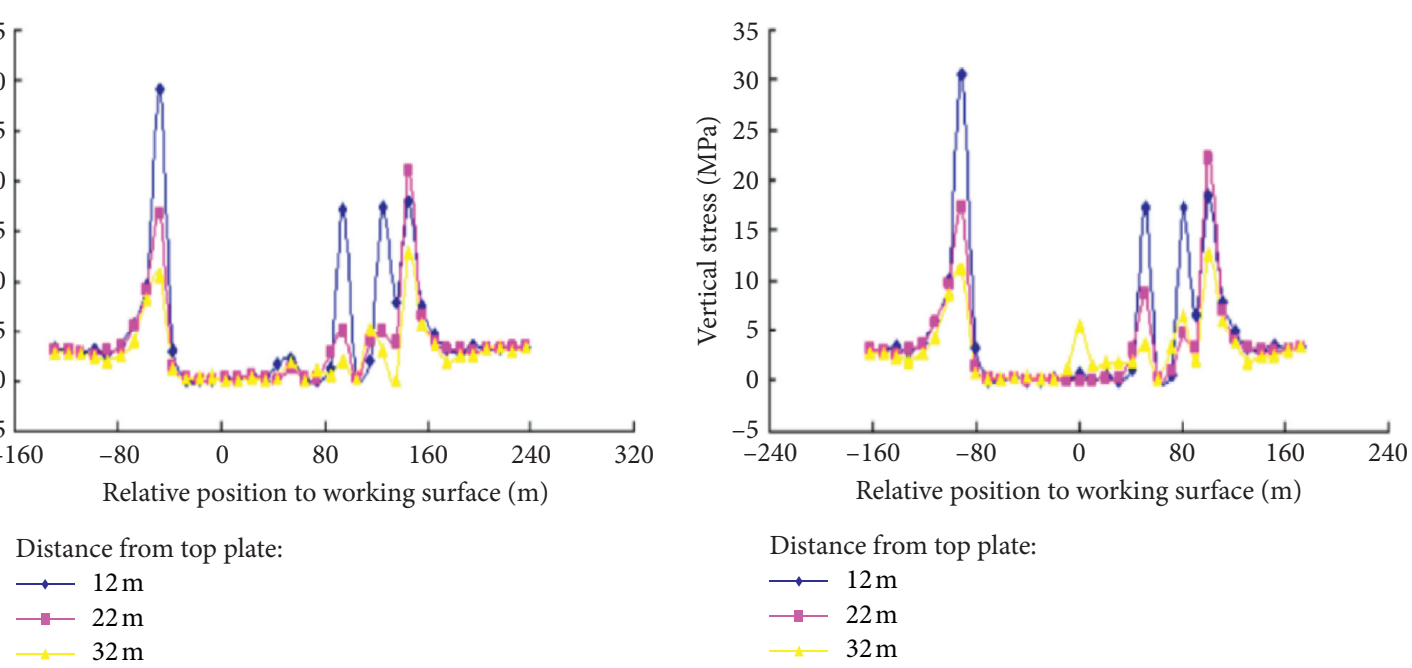

Distance from top plate:

$\longrightarrow 12 \mathrm{~m}$

$\because-22 \mathrm{~m}$

$\longrightarrow 32 \mathrm{~m}$

(e)
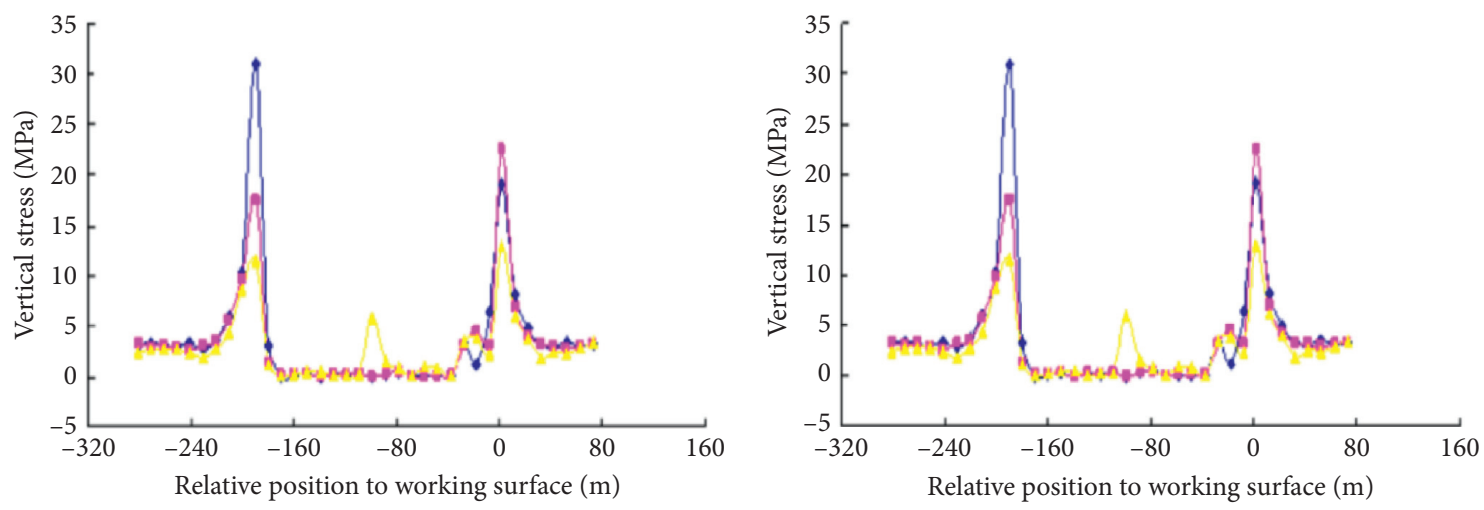

Distance from top plate:

Distance from top plate:

$\longrightarrow 12 \mathrm{~m}$
$\because-22 \mathrm{~m}$
$\longrightarrow 32 \mathrm{~m}$

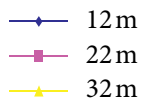

(g)

(h)

Figure 14: (a) Stress distribution diagram of the fourth-level mining approach; (b) stress distribution diagram of the eighth-level mining approach, (c) stress distribution diagram of the twelfth-level mining approach; (d) stress distribution diagram of the seventeenth-level mining approach; (e) stress distribution diagram of the fourth-level recovery route; (f) stress distribution diagram of the eighth-level recovery route; (g) stress distribution diagram of the twelfth-level recovery route; and (h) stress distribution diagram of the sixteenth-level recovery route. 
goaf. (2) The displacement of the overlying strata decreased as the height of the roof increased. (3) The stress in the overlying strata of the stope constantly changed. As the working face advanced, the overburden stress near the working face increased.

\section{Conclusions}

In this study the deformation and failure laws of the surrounding roof rock and the characteristics of the surface subsidence were systematically investigated. The following conclusions were drawn:

(1) Based on the existing underground mining method and the actual situation of the Jinning Phosphate Mine, an improved pillarless sublevel caving method is proposed. It greatly improves the ore recovery rate and reduces the cost of filling.

(2) The similar simulation experimental results show that the deformation and failure of the overburden strata start directly from the roof of the goaf and then gradually develop into the deep part of the overburden strata, forming an irregular trapezoidal collapse zone above the goaf. The maximum surface subsidence is located directly above the goaf, and the position of the maximum subsidence gradually moves in the forward direction of the stope.

(3) The numerical simulation results show that the movement of the overlying strata is nonlinear. The subsidence displacement of the overlying strata decreases with increasing stope roof height. A support pressure concentration area forms within a certain range of the stope roof. The numerical simulation results are basically the same as the similar simulation experimental results.

\section{Data Availability}

The data used to support the findings of this study are included within the article.

\section{Conflicts of Interest}

The authors declare that there are no conflicts of interest regarding the publication of this paper.

\section{Authors' Contributions}

Conceptualization and software were done by Xiaoshuang $\mathrm{Li}$; method and formal analysis were done by Qihang Li; original draft was prepared by Weijun Tian; and review and editing were done by Jiabo Geng and Tao Zhou.

\section{Acknowledgments}

The authors acknowledge the support provided by the National Natural Science Foundation of China (nos. 41702327 and 41867033), Postdoctoral Science Foundation of China (no. 2019M650144), and State Key Laboratory of Safety and Health for Metal Mines (no. zdsys2019-005).

\section{References}

[1] Q. F. Ge, X. S. Sun, W. G. Zhu, and Q. G. Chen, "Research of mining method for difficult-to-mine ore bodies in deep mine," Advanced Materials Research, vol. 962-965, pp. 1041-1046, 2014.

[2] R. N. Scoon and A. A. Mitchell, "A multi-stage orthomagmatic and partial melting hypothesis for the driekop platiniferous dunite pipe, eastern limb of the bushveld complex, south Africa," South African Journal of Geology, vol. 112, no. 2, pp. 163-186, 2009.

[3] A. Belkabir, H. L Gibson, E. Marcoux, D. Lentz, and S. Rziki, "'Geology and wall rock alteration at the Hercynian Draa Sfar $\mathrm{Zn}-\mathrm{Pb}-\mathrm{Cu}$ massive sulphide deposit," Morocco," Ore Geology Reviews, vol. 33, no. 3-4, pp. 280-306, 2008.

[4] A. H Abbas, "Environmental impacts of the gyp-sum mining operation at Maqna area, Tabuk, Saudi Arabia," Environmental Geology, vol. 41, no. 1-2, pp. 209-218, 2001.

[5] I. N Economopoulos and A. G. Vgenopoulos, "An approach concerning bauxites, bauxitization processes and mining in Greece," Oryktos Ploutos, vol. 109, pp. 21-34, 1998.

[6] W. Zhu, L. Chen, Z. Zhou, B. Shen, and Y. Xu, "Failure propagation of pillars and roof in a room and pillar mine induced by longwall mining in the lower seam," Rock Mechanics and Rock Engineering, vol. 52, no. 4, pp. 1193-1209, 2019.

[7] K. Skrzypkowski, W. Korzeniowski, K. Zagórski, and A. Zagórska, "Adjustment of the yielding system of mechanical rock bolts for room and pillar mining method in stratified rock mass," Energies, vol. 13, no. 8, p. 2082, 2020.

[8] M. A. A. Marzouk, D. Li, G. F. Ren, and C. R. Zhang, "Estimating deterioration rate of some carbonate rocks used as building materials under repeated frost damage process, China," Advances in Materials Science and Engineering, vol. 13, pp. 1-13, 2020.

[9] K. Ding, F. S. Ma, H. J. Zhao, J. Guo, J. J. Zhu, and M. H. Tian, "Monitoring and mechanism of ground movement and fissures formed by block caving and sublevel filling in the jingerquan nickel mine, China," International Journal of Simulation. Systems, Science and Technology, vol. 17, no. 22, 2016.

[10] C. F Du, J. H. Du, L. W. Guo, and G. Y. Tang, "Mechanism of capping rock collapse by no-pillar sublevel caving," Journal of University of Science and Technology Beijing, vol. 31, no. 6, pp. 667-673, 2009.

[11] Z. Y. Rui, "Technical economy and environmental protection of converting open-pit mining to underground mining," World Mining Equipment, vol. 6, pp. 13-19, 1999.

[12] S. C. Ren, "Determination of mining methods in the transition period of baiyin super large copper mine from open-pit to underground," Non-ferrous Mines, vol. 6, pp. 1-7, 1995.

[13] Z. Xia, Z. Tan, and Y. Miao, "Damage evolution mechanism of extraction structure during mining gently dipped orebody by block caving method," Geotechnical \& Geological Engineering, vol. 38, no. 4, pp. 3891-3902, 2020.

[14] X.-q. Wang, X.-r. Meng, Z.-n. Gao, and Z.-h. Liu, "Optimal location of terminal line in sublevel caving face with suspendshift support in thinner thick-seam," Journal of Coal Science and Engineering, vol. 14, no. 4, pp. 600-603, 2008.

[15] B. Li, M. G. Xu, H. B. Cao, and Y. Li, "J. MA. "Numerical simulation to optimize the drawing pace of sublevel caving without sill pillar", " Mining Research And Development, vol. 2, pp. 5-7, 2012. 
[16] Y. Y. Ruan, D. S. He, and R. Chi, "Review on beneficiation techniques and reagents used for phosphate ores," Minerals, vol. 9, no. 4, p. 253, 2019.

[17] G. Carbajal-Franco, E. Rendón-Lara, I. M. Abundez-Barrera, and A. Vásquez-Aguilar, "The mining of materials with similar electronic properties from the Crystallographic Open Database (COD)," Materials Research Express, vol. 7, no. 3, Article ID 035903, 2020.

[18] W.-b. Sun, F. Zhou, J.-l. Shao, H.-q. Du, and Y.-c. Xue, "Development status and prospects of mine physical similar material simulation experiments," Geotechnical \& Geological Engineering, vol. 37, no. 4, pp. 3025-3036, 2019.

[19] S. Chen, H. Wang, J. Zhang, H. Xing, and H. Wang, "Experimental study on low-strength similar-material proportioning and properties for coal mining," Advances in Materials Science and Engineering, vol. 2015, Article ID 696501, 6 pages, 2015.

[20] K. Ciarkowska, L. Gargiulo, and G. Mele, "Natural restoration of soils on mine heaps with similar technogenic parent material: a case study of long-term soil evolution in SilesianKrakow Upland Poland," Geoderma, vol. 261, pp. 141-150, 2016.

[21] Y. L. Jiang, D. F. Zhang, K. Wang, and X. Q. Zhang, "Mininginduced damage characteristics of floors during fully mechanized caving mining: a case study," Advances in Materials Science and Engineering, vol. 2018, Article ID 1513451, 11 pages, 2018.

[22] X. S. Li, Y. M. Wang, and K. Zhao, "Study on the law of ground pressure obliquity effect with gently inclined thin to medium thickness phosphate body from open-pit to underground," Solid State Technology, vol. 63, no. 4, pp. 6773-6781, 2020.

[23] X. S. Li, Y. M. Wang, and K. Zhao, "Research on deformation and failure character of underground surrounding rock and overlying strata transition from open-pit to underground mining," Solid State Technology, vol. 63, no. 4, pp. 6732-6757, 2020.

[24] W.-X. Li, C.-Y. Gao, X. Yin, J.-F. Li, D. L. Qi, and J.-C. Ren, “A visco-elastic theoretical model for analysis of dynamic ground subsidence due to deep underground mining," Applied Mathematical Modelling, vol. 39, no. 18, pp. 5495-5506, 2015.

[25] Y. Lin, "Research on computer stochastic simulation of large spacing pillar-less mining ore drawing," Journal of Physics: Conference Series, vol. 1649, Article ID 012023, 2020.

[26] C. B. Zhou, N. Jiang, and G. Luo, "Study on blasting vibration cumulative damage effect of medium-length hole mining," Disaster Advances, vol. 5, no. 4, pp. 468-473, 2012.

[27] W. X. Li, Q. L. Meng, L. Wen, X. M. Liu, and L. Liu, “Analysis of horizontal stress field and far field movements due to deep mining," Chinese Journal of Rock Mechanics and Engineering, vol. 29, no. 1, pp. 2630-2636, 2010.

[28] Y. L. Fang, "UDEC numerical simulation research of mining overlying strata movement regulation," Applied Mechanics and Materials, vol. 448-453, pp. 3884-3887, 2013.

[29] K. Moses and Y. Y. Xia, "UDEC-based stability analysis of jointed bedding slope and slope parameter optimization suggestions: a case study," SN Applied Sciences, vol. 2, no. 12, p. $1943,2020$.

[30] S. T Gu, Z. M Xiao, B. Y. Jiang, R. F. Huang, and P. Shan, "Research of rock burst risk induced by mining and field case in anticlinal control area," Advances in Civil Engineering, vol. 2018, Article ID 2632549, 10 pages, 2018.
[31] H. Jiang, "Simple three-dimensional Mohr-Coulomb criteria for intact rocks," International Journal of Rock Mechanics and Mining Sciences, vol. 105, pp. 145-159, 2018.

[32] T. Yu, "Statistical damage constitutive model of quasi-brittle materials," Journal of Aerospace Engineering, vol. 22, no. 1, pp. 95-100, 2009.

[33] P. Moczko, D. Pietrusiak, and J. Wieckowski, "Investigation of the failure of the bucket wheel excavator bridge conveyor," Engineering Failure Analysis, vol. 106, Article ID 104180, 2019.

[34] M. A. Sonnov, A. E. Rumyantsev, A. V. Trofimov, and V. B. Vilchinsky, "Numerical modeling of stress-and-strain behaviour of deposit deformed by mining operations using step-by-step calculation function in the CAE fidesys software system," Mining Industry Journal/Gornaia Promyshlennost, vol. 2020, no. 2, pp. 110-114, 2020.

[35] G. Liu, X.-T. Feng, Q. Jiang, Z. Yao, and S. Li, "In situ observation of spalling process of intact rock mass at large cavern excavation," Engineering Geology, vol. 226, pp. 52-69, 2017.

[36] S.-R. Wang and J.-L. Feng, "3D deformation effect and optimal excavated design of surface mine," Journal of Coal Science and Engineering, vol. 15, no. 4, pp. 361-366, 2009.

[37] X. S. Li, Y. M. Wang, K. Zhao, and S. Yang, "Research progress on the Key problems in transition from open-pit to underground mining for metal mines," Metal Mine, vol. 2019, no. 12, pp. 12-20, 2019.

[38] X. S. Li, K. Peng, J. Peng, and D. Hou, "Effect of thermal damage on mechanical behavior of a fine-grained sandstone," Arabian Journal of Geosciences, vol. 14, p. 1212, 2021.

[39] X. S. Li, Z. F. Liu, and S. Yang, "Similar physical modeling of roof stress and subsidence in room and pillar mining of a gently inclined medium-thick phosphate rock," Advances in Civil Engineering, vol. 2021, Article ID 6686981, 17 pages, 2021.

[40] X. S. Li, S. Yang, Y. Wang, W. Nie, and Z. Liu, "Macro-micro response characteristics of surrounding rock and overlying strata towards the transition from open-pit to underground mining," Geofluids, vol. 2021, Article ID 5582218, 18 pages, 2021. 